\title{
The Mechanisms of the Atlantic Meridional Overturning Circulation Slowdown Induced by Arctic Sea Ice Decline ${ }^{\mathscr{O}}$
}

\author{
WEI LIU \\ Department of Earth Sciences, University of California Riverside, Riverside, California, and \\ Department of Geology and Geophysics, Yale University, New Haven, Connecticut \\ AleXey Fedorov \\ Department of Geology and Geophysics, Yale University, New Haven, Connecticut \\ FLORIAN SÉVELLEC \\ Laboratoire d'Océanographie Physique et Spatiale, CNRS, Univ.-Brest IRD, Brest, France, and \\ Ocean and Earth Science, University of Southampton, Southampton, United Kingdom
}

(Manuscript received 15 April 2018, in final form 6 November 2018)

\begin{abstract}
We explore the mechanisms by which Arctic sea ice decline affects the Atlantic meridional overturning circulation (AMOC) in a suite of numerical experiments perturbing the Arctic sea ice radiative budget within a fully coupled climate model. The imposed perturbations act to increase the amount of heat available to melt ice, leading to a rapid Arctic sea ice retreat within 5 years after the perturbations are activated. In response, the AMOC gradually weakens over the next $\sim 100$ years. The AMOC changes can be explained by the accumulation in the Arctic and subsequent downstream propagation to the North Atlantic of buoyancy anomalies controlled by temperature and salinity. Initially, during the first decade or so, the Arctic sea ice loss results in anomalous positive heat and salinity fluxes in the subpolar North Atlantic, inducing positive temperature and salinity anomalies over the regions of oceanic deep convection. At first, these anomalies largely compensate one another, leading to a minimal change in upper ocean density and deep convection in the North Atlantic. Over the following years, however, more anomalous warm water accumulates in the Arctic and spreads to the North Atlantic. At the same time, freshwater that accumulates from seasonal sea ice melting over most of the upper Arctic Ocean also spreads southward, reaching as far as south of Iceland. These warm and fresh anomalies reduce upper ocean density and suppress oceanic deep convection. The thermal and haline contributions to these buoyancy anomalies, and therefore to the AMOC slowdown during this period, are found to have similar magnitudes. We also find that the related changes in horizontal winddriven circulation could potentially push freshwater away from the deep convection areas and hence strengthen the AMOC, but this effect is overwhelmed by mean advection.
\end{abstract}

\section{Introduction}

Anthropogenic climate change is already affecting various components of Earth's climate system, especially in the northern high latitudes. According to satellite-based data, Arctic sea ice has been declining over the past three decades (Stroeve et al. 2007; Parkinson and Cavalieri 2008;

Supplemental information related to this paper is available at the Journals Online website: https://doi.org/10.1175/JCLID-18-0231.s1.

Corresponding author: Wei Liu, wei.liu@ucr.edu
Ding et al. 2017) with a reduction of annual mean ice cover of over $15 \%$ (relative to the first decade, 1979-88) (Fig. 1c, green curve). Pronounced sea ice loss has occurred in the East Siberian, Laptev, Kara, and Barents Seas (Figs. 1a,b). In parallel, the Atlantic meridional overturning circulation (AMOC), a key component of global ocean circulation related to deep water formation in the subpolar North Atlantic, has slowed down after 2004 (Fig. 1c, purple curve) as measured by the Rapid Climate Change-Meridional Overturning Circulation and Heatflux Array (RAPID-MOCHA) at $26.5^{\circ} \mathrm{N}$ (Smeed et al. 2014; Srokosz and Bryden 2015; Smeed et al. 2018). While these (multi)decadal Arctic sea ice and AMOC 
(a) SIC (NSIDC, 1979-1988)

(b) SIC (NSIDC, 2005-2014)

(c) (b)-(a)

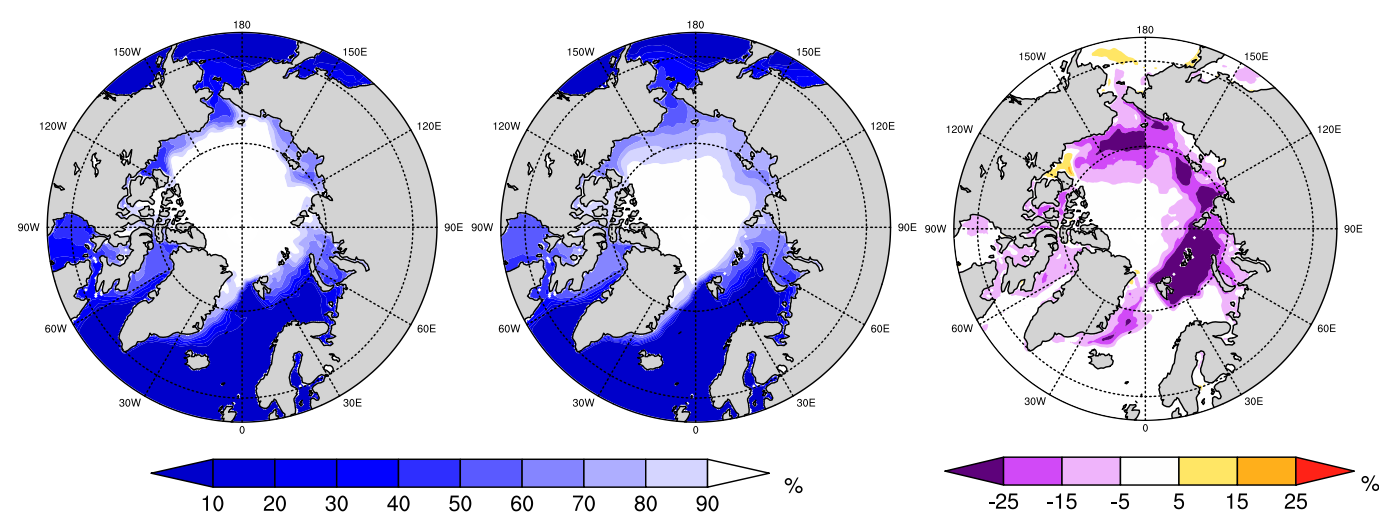

(d) Arctic SIE (NSIDC) \& AMOC (RAPID)

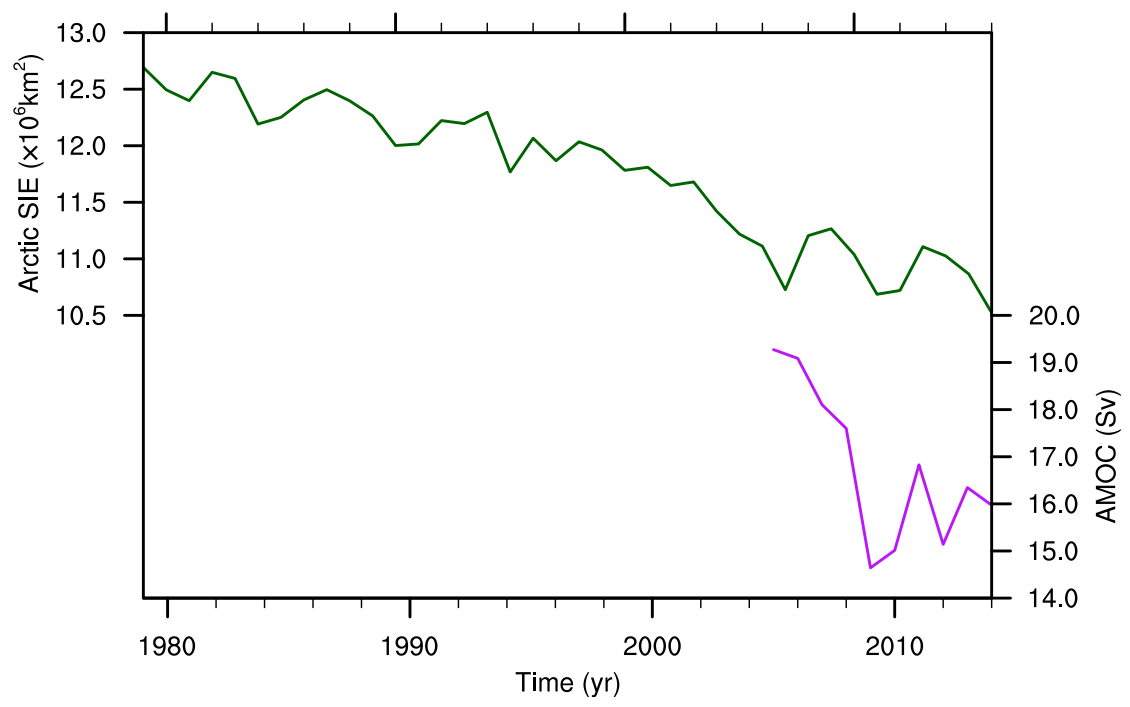

FIG. 1. Annual mean SIC (color shading; \%) for two periods, (a) 1979-88 and (b) 2005-14, as derived from the satellite-based passive microwave data provided by the NSIDC and (c) the difference between the two periods. (d) Annual mean Arctic SIE since 1979 (green) and AMOC volume transport observed from the RAPID-MOCHA array along $26.5^{\circ} \mathrm{N}$ in the North Atlantic (purple). SIE is defined as the area of the ocean with ice concentration above 15\%. Panels (a), (b), and (d) are reproduced from Sévellec et al. (2017).

observations are too short to infer long-term trends in view of natural climate variability (e.g., Swart et al. 2015; Roberts et al. 2014), reconstructed historical data (Titchner and Rayner 2014; Rahmstorf et al. 2015; Sévellec et al. 2017; Caesar et al. 2018) suggest a longterm, centennial decline in the two climate components. Furthermore, climate models predict even greater Arctic sea ice retreat and AMOC weakening in the future [e.g., the Fifth Assessment Report of the Intergovernmental Panel on Climate Change (IPCC AR5)], which supports the notion of a long-term decline of Arctic sea ice and the AMOC.

These two phenomena-the Arctic sea ice decline and AMOC slowdown-have been typically considered as separate climate responses to anthropogenic warming. In particular, the AMOC slowdown has been attributed primarily to increased upper-ocean stratification caused by anomalous surface heat fluxes in the subpolar North Atlantic due to anthropogenic warming (e.g., Gregory et al. 2005; Bakker et al. 2016; Liu et al. 2017) and partially (Bakker et al. 2016) by freshwater discharge from Greenland ice sheet melting (e.g., Jungclaus et al. 2006; Mikolajewicz et al. 2007; Hu et al. 2009). A question arises: could Arctic sea ice decline also play a role in the AMOC slowdown?

A number of studies have begun to explore the role of Arctic processes in modulating the AMOC. Early studies (e.g., Delworth et al. 1997; Häkkinen 1993; Häkkinen 1999; 
Zhang and Vallis 2006) focusing on the "Great Salinity Anomalies" (GSAs; cf. Dickson et al. 1988) suggested that Arctic sea ice changes could be the origin of the GSAs that propagate into the subpolar North Atlantic and drive AMOC multidecadal variability via the mechanisms described for example by Sévellec et al. (2008) and Sévellec and Fedorov (2015). The freshening within the upper $500-800 \mathrm{~m}$ induced by the GSAs can inhibit deep convection and reduce the AMOC strength (Jungclaus et al. 2005; Sévellec and Fedorov 2015). Several studies (e.g., $\mathrm{Hu}$ et al. 2004, 2013; Jahn and Holland 2013; Gervais et al. 2018) have shown that such freshwater effects can also work under global warming scenarios. On the other hand, Levermann et al. (2007) suggested a thermal effect of Arctic sea ice on AMOC variations based on the fact that changes in sea ice cover could modulate heat loss from the ocean.

Recently, Sévellec et al. (2017) have conducted an adjoint sensitivity analysis within a realistic ocean model to show that both the thermal and freshwater effects caused by Arctic sea ice decline could influence the AMOC. They argue that the Arctic sea ice loss will increase the area of open ocean, allowing more solar radiation and greater freshwater fluxes into the ocean. Thereby, positive buoyancy anomalies can be generated in the Arctic, which will spread over the North Atlantic and lead to an AMOC weakening after several decades. In addition to the study of Sévellec et al. (2017), a similar AMOC behavior with Arctic sea ice loss has been also discussed in Scinocca et al. (2009), Oudar et al. (2017), and Sun et al. (2018). Nevertheless, the details and physical processes of how Arctic sea ice influences the AMOC and the relative importance of thermal and freshwater effects due to sea ice decline remain unclear in a fully coupled climate system.

To further investigate the effect of contracting sea ice cover on the AMOC, here we conduct a suite of sensitivity experiments wherein we perturb Arctic sea ice extent by modifying sea ice radiative properties (albedo, emissivity) in a fully coupled climate system. Our approach is different from previous diagnostic analyses in that we exclude the effect of anthropogenic warming from consideration and, to modify sea ice extent, alter sea ice radiative budget directly. Through this approach, we are able to isolate the effects of Arctic sea ice loss on the AMOC and assess the separate roles of the thermal and haline forcings.

The structure of the paper is as follows. In section 2, we introduce the observations and the climate model employed in this study and describe the sea ice perturbation experiments. The results are summarized in section 3, and the discussion of the results and conclusions are given in section 4 .

\section{Observations and model experiments}

\section{a. Arctic sea ice and AMOC observations}

We use passive microwave sea ice concentration measurements from the National Snow and Ice Data Center (NSIDC), which are based on gridded brightness temperatures from the Defense Meteorological Satellite Program (DMSP) series of passive microwave radiometers: the Special Sensor Microwave Imager (SSM/I) and the Special Sensor Microwave Imager/ Sounder (SSM/IS). The sea ice concentration dataset is produced by combining concentration estimates from two algorithms developed at the NASA Goddard Space Flight Center (GSFC): the NASA Team algorithm and the bootstrap algorithm. It is gridded on the NSIDC polar stereographic grid with $25 \mathrm{~km} \times 25 \mathrm{~km}$ grid cells. We use annual mean values of sea ice concentration (SIC; Figs. 1a,b) and sea ice extent (SIE; Fig. 1d), since they are representative of the extent of open water in the Arctic. Typically, sea ice extent is defined as the area of the ocean with ice concentration above 15\%. During 1979-2014, the Arctic sea ice extent was declining at an average rate of $5.3 \times 10^{5} \mathrm{~km}^{2}$ per decade (Fig. 1d).

We also use AMOC observations from the RAPIDMOCHA monitoring system deployed along $26.5^{\circ} \mathrm{N}$ in the North Atlantic, which has been continuously observing the AMOC since 2004. We use annual mean values estimated from the RAPID-MOCHA observations and atmospheric wind products (which provide Ekman flow). During 2005-14, the linear trend of annual mean AMOC strength was about $-4 \mathrm{~Sv}(1 \mathrm{~Sv} \equiv$ $10^{6} \mathrm{~m}^{3} \mathrm{~s}^{-1}$ ) per decade (Fig. 1d). Even though this strong decadal AMOC decline is likely to reflect natural decadal variability, the RAPID-MOCHA observations are consistent with reconstructed historical data (Titchner and Rayner 2014; Rahmstorf et al. 2015; Sévellec et al. 2017; Caesar et al. 2018), which suggests a secular, long-term decline of the AMOC over the twentieth and the early twenty-first centuries.

\section{b. Observed and simulated mixed layer depth}

We use the mixed layer depth (MLD) in March to indicate deep convection in the North Atlantic that is associated with deep water formation and the strength of the AMOC (Hu et al. 2008; Liu and Liu 2013). The observed MLD climatology is adopted from the Monthly Isopycnal/Mixed-Layer Ocean Climatology (MIMOC) data (Schmidtko et al. 2013), which have global coverage, with a $0.5^{\circ} \times 0.5^{\circ}$ resolution and are mostly based on Argo conductivity-temperaturedepth (CTD) data and supplemented by historical shipboard and ice-tethered profiler CTD data. This MLD observation shows that wintertime deep 
(a) MLD (MIMOC)

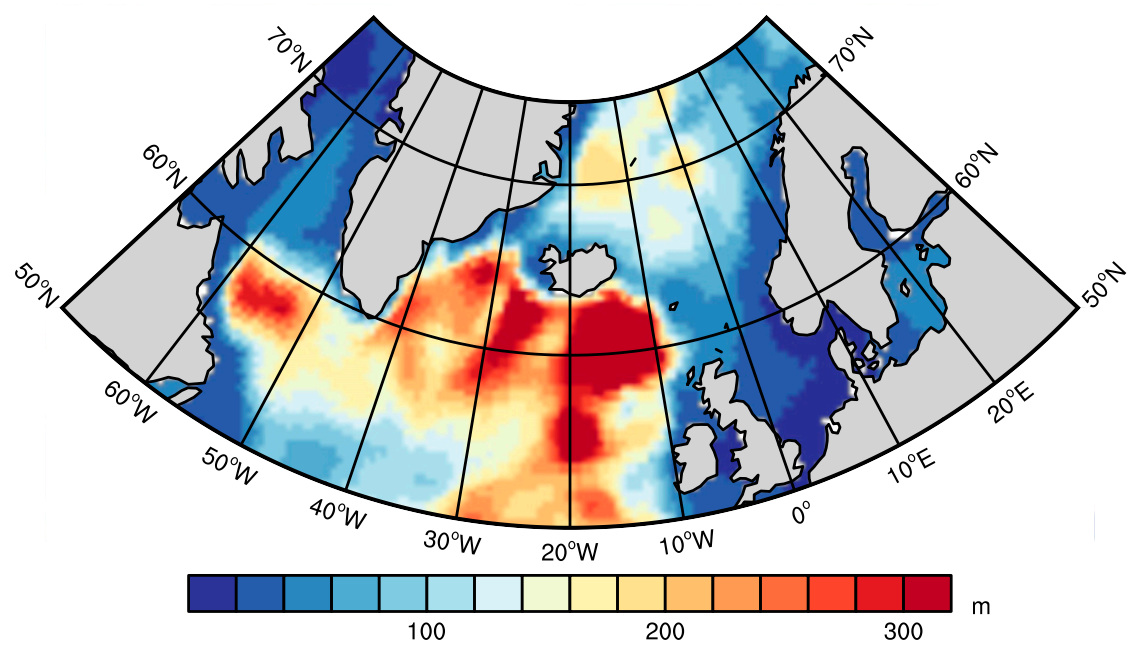

(b) MLD \& (U,V) (CTRL)

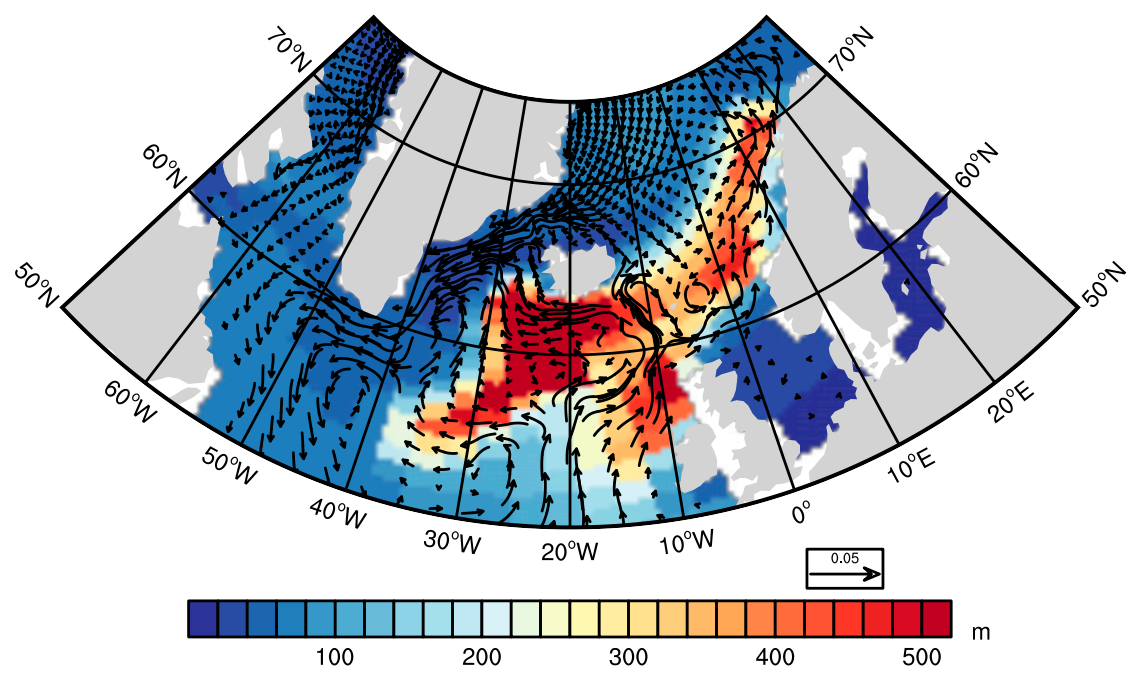

FIG. 2. MLD in March (color shading; $m$ ) from the (a) MIMOC observation and (b) CESM1_T31_gx3v7 preindustrial control run (CTRL). Annual mean ocean currents (vectors; $\mathrm{m} \mathrm{s}^{-1}$ ) averaged over upper $1000 \mathrm{~m}$ in the CTRL are also shown in (b). Note that different color bar scales are used for each panel.

convection in the North Atlantic mostly occurs to the south of Iceland, in the Irminger Sea and Labrador Sea, and in the Greenland-Iceland-Norwegian (GIN) Seas (Fig. 2a). Besides, we examine the simulated MLD climatology from 12 coupled climate models participating in phase 5 of the Coupled Model Intercomparison Project (CMIP5) (see Table S1 in the online supplemental material), which is calculated as a $50-\mathrm{yr}$ average from the preindustrial simulation of each model. As shown in Fig. S1 (also in the online supplemental material), wintertime deep convection sites in the North Atlantic vary among CMIP5 models and are different from the observations (a point to return later).

\section{c. CESM configuration}

The coupled climate model employed in this study is the Community Earth System Model (CESM), version 1.0.4, maintained by the National Center for Atmospheric Research (NCAR). It is denoted as CESM1_T31_gx3v7 in the paper to be differentiated from CESM1-CAM5 and CESM1-BGC in the CMIP5. The atmosphere component is the Community Atmosphere Model, version 4 (CAM4) (Neale et al. 2010), with a T31 spectral dynamical core 
(horizontal grid of $3.75^{\circ} \times 3.75^{\circ}$ ) and 26 layers in the vertical. CAM4 includes a turbulent mountain stress parameterization, which significantly improves coupled atmosphere-ocean interactions and ocean surface stress. The land component is the Community Land Model, version 4 (CLM4) (Lawrence et al. 2012), with a T31 spectral truncation.

The ocean component is the Parallel Ocean Program, version 2 (POP2) (Smith et al. 2010), which employs a nominal $3^{\circ}$ irregular horizontal grid and 60 layers in the vertical. The horizontal resolution becomes significantly finer toward Greenland and in the Arctic $\left(\sim 1^{\circ}\right)$, which enables POP2 to better resolve ocean topography in high latitudes. This ocean model also includes a new overflow parameterization of density-driven flows (such as the Denmark Strait overflow), which not only represents the exchanges through narrow straits and channels, associated entrainment, and subsequent injection of overflow product waters into the abyssal basins, but also improves the shallow penetration depth bias for deep water.

In the paper, the AMOC strength is defined as the maximum of the annual mean meridional streamfunction below $500 \mathrm{~m}$ in the North Atlantic. The mean value of the AMOC strength is $17.5 \mathrm{~Sv}$ in the model's preindustrial control simulation, which is well consistent with the RAPID-MOCHA observations. In CESM1_T31_gx3v7, wintertime deep convection in the North Atlantic occurs in the Norwegian Sea and extends to a region south of Iceland and east of the British Isles (Fig. 2b). Compared with the observation (Fig. 2a), this model successfully captures the deep convection to the south of Iceland but does not represent the deep convection farther west in the Irminger Sea and Labrador Sea.

The sea ice component of the model is the Community Ice Code, version 4 (CICE4) (Holland et al. 2012), sharing the same horizontal grid with the ocean component. Sea ice albedo is computed using parameters representing optical properties of snow, bare sea ice, and melt ponds where the parameters are based on standard deviations from data provided by the Surface Heat Budget of the Arctic (SHEBA) (Uttal et al. 2002). We find that this version of CESM simulates a larger sea ice area than the observation (Fig. S2), which is a common feature of lower-resolution configurations of the CESM family (Shields et al. 2012). However, since we examine the difference between the perturbation experiments and the control simulation rather than the control simulation itself, the impact of this bias is expected to be relatively small in our results. To evaluate Arctic sea ice changes in the model, we calculate the total area of sea ice (defined as the net area of the ocean fully covered with ice) by integrating ice fraction over the entire region of the ocean where ice forms. We use this metric because it is independent of model grid and resolution (Eisenman et al. 2011) and can precisely describe the changes between sea ice and open water. The latter is critical for computing solar radiation and freshwater fluxes entering the ocean and affecting the AMOC.

\section{d. Perturbation experiments}

To induce Arctic sea ice contraction, we perturb the snow-sea ice radiation balance, which allows us to modulate the spatial structure and magnitude of Arctic sea ice and assess the impacts of sea ice change on the AMOC. We adopt two independent approaches. In the first approach we reduce the net reflectivity (albedo) of sea ice and snow, which increases absorbed shortwave radiation. In the second one, we reduce the emissivity of sea ice and overlying snow, which decreases outgoing longwave radiation. The perturbation experiments start from a CESM quasi-equilibrium preindustrial control simulation (CTRL); a perturbation to sea ice radiative properties is applied instantaneously at time zero and maintained for 200 years of integration. Since perturbing sea ice radiative properties is the only model modification relative to the CTRL, all changes in the experiments can be attributed to the changes in Arctic sea ice. Our perturbation experiments are along with previous studies aiming to investigate sea ice effects via altering ice albedo (Bitz et al. 2006; Scinocca et al. 2009; Graversen and Wang 2009; Blackport and Kushner 2016, 2017; Cvijanovic et al. 2017), fixing sea ice concentration (Suo et al. 2017; Sun et al. 2018), or nudging sea ice to a future equilibrium state (Deser et al. 2015; Tomas et al. 2016; Oudar et al. 2017; McCusker et al. 2017; Smith et al. 2017; Wang et al. 2018).

By testing different parameters of sea ice/snow reflectivity and emissivity, we have arrived at two baseline experiments that closely replicate the observed Arctic sea ice loss over the past several decades (Fig. 3). The first baseline experiment is named the SW experiment, in which we modify the optical properties of snow, bare sea ice, and ponded ice over the Arctic area in the deltaEddington solar radiation treatment within the model sea ice component. Particularly, we reduce the single scattering albedo (the probability that a single event results in scattering) of snow by $10 \%$ for all spectral bands and adjust the optical properties of bare ice and ponded ice by changing the standard deviation parameters $\left(R_{\text {ice }}\right.$ and $\left.R_{\text {pnd }}\right)$ from 0 to -2 . The second baseline experiment is named the LW experiment, in which we reduce the emissivity of snow and ice by a factor of $10^{-4}$ over the Arctic area. Since no modifications are applied over open water and in the Southern Hemisphere, the 
(a) CTRL (ann)

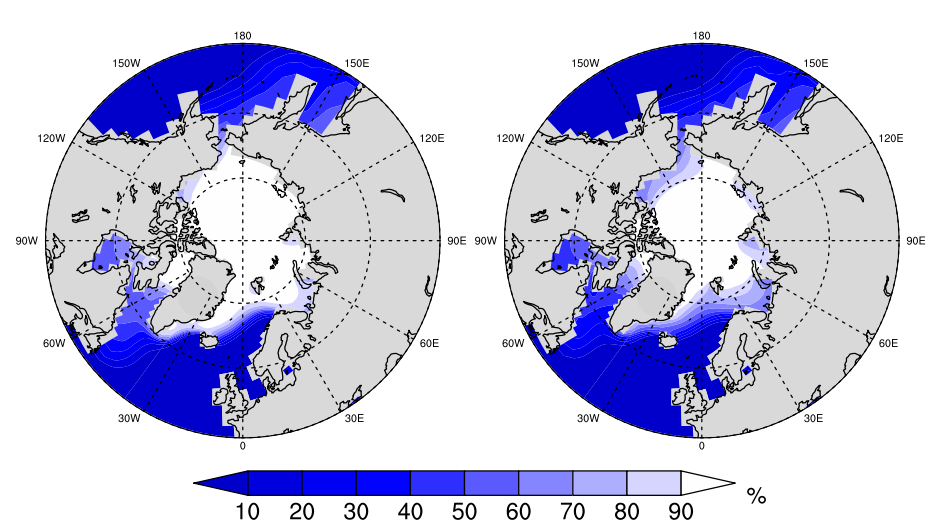

(c) (b)-(a)

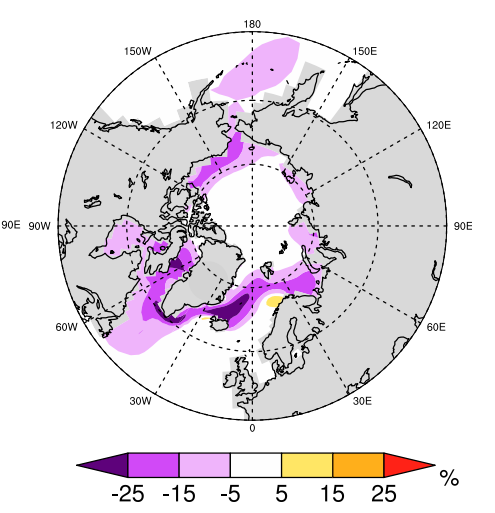

(d) Arctic SIA reduction

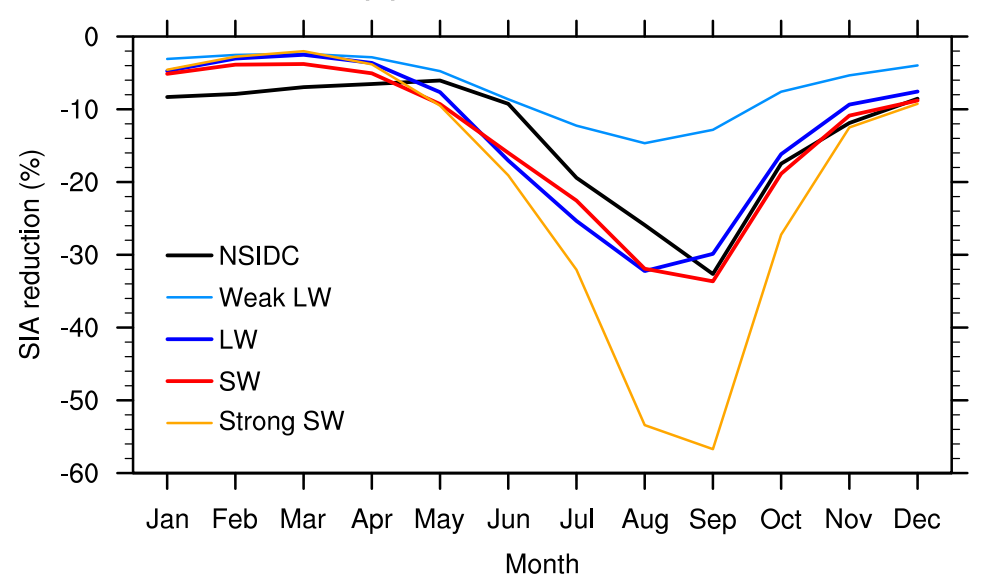

FIG. 3. Annual mean SIC (color shading; \%) in the (a) CTRL and (b) SW experiments and (c) the difference between the two experiments. (d) Relative decline (\%) of total SIA for different months of the year in the Weak LW (light blue), LW (blue), SW (red), and Strong SW (orange) experiments, and the observations from the NSIDC (black). The observations reflect the difference between 2005-14 and 1979-88. The experimental results show the mean difference between the last 50 years of each experiment relative to 50 years of the CTRL. Perturbations to sea ice radiative balance are applied instantaneously at time zero and then maintained for the duration of each perturbation experiment. Panels (a) and (b) and the black, blue, and red curves in (d) are reproduced from Sévellec et al. (2017).

main result of the above experiments is sea ice contraction at the ice margins in the northern high latitudes.

In addition to the two baseline experiments, we have also completed two more sensitivity experiments: one using a stronger perturbation in the shortwave component (referred to as Strong SW) and another using a weaker perturbation in the longwave component (referred to as Weak LW). In the Strong SW experiment, we reduce the single scattering albedo by $30 \%$ for snow and adjust the optical properties of bare ice and ponded ice by changing the standard deviation parameters $\left(R_{\text {ice }}\right.$ and $R_{\text {pnd }}$ ) from 0 to -4 . In the Weak LW experiment, we reduce the emissivity of snow and ice by a factor of 0.4 . The parameters of these additional experiments are chosen to yield a sufficiently broad range of changes in
Arctic sea ice (Fig. 3d). The key model parameters used in the experimental setup are summarized in Table 1.

\section{Results}

\section{a. Arctic sea ice loss and the resultant AMOC weakening}

Arctic sea ice shows a rapid response to perturbations in sea ice radiative properties. In both SW and LW experiments, the annual mean Arctic sea ice area (SIA) rapidly decreases from $15.7 \times 10^{6}$ to $13.7 \times 10^{6} \mathrm{~km}^{2}$ within the first 5 years of integration but then stays relatively constant (except for natural variability) through the rest of 200-yr simulations (red and blue curves; 
TABLE 1. The parameters and other details of the experiments. The snow albedo shows the ratio of the single scattering albedo in individual runs to the default albedo value used in the CESM1_T31_gx3v7 control run (CTRL). The albedo of bare and ponded ice is tuned by modifying the standard deviation parameters of $R_{\mathrm{ice}}$ and $R_{\mathrm{pnd}}$. The emissivity of snow and ice in longwave experiments is changed by a factor of 0.6 or $10^{-4}$ relative to the CTRL. The Arctic SIA $\left(10^{6} \mathrm{~km}^{2}\right)$ and AMOC strength (Sv) are calculated as a 50 -yr mean for the CTRL and an average for the last 50 years in perturbation experiments. Both September (Sep) and annual mean (ann) Arctic SIAs are shown.

\begin{tabular}{|c|c|c|c|c|c|c|}
\hline Runs & Snow albedo & Ice albedo $\left(R_{\text {ice }}, R_{\text {pnd }}\right)$ & Snow/ice emissivity & Arctic SIA (Sep) & Arctic SIA (ann) & AMOC \\
\hline CTRL & 1.0 & 0 & 1.0 & 10.5 & 15.7 & 17.4 \\
\hline Weak LW & 1.0 & 0 & 0.6 & 9.1 & 14.8 & 14.5 \\
\hline LW & 1.0 & 0 & $10^{-4}$ & 7.4 & 13.9 & 10.7 \\
\hline SW & 0.9 & -2.0 & 1.0 & 7.1 & 13.8 & 11.5 \\
\hline Strong SW & 0.7 & -4.0 & 1.0 & 4.5 & 13.3 & 8.1 \\
\hline
\end{tabular}

Fig. 4a). Comparing the last 50-yr average for the SW or LW experiment with a 50-yr mean in the CTRL, we find that each experiment simulates an Arctic sea ice decline similar to the observed between the periods of 1979-88 and 2005-14 in terms of both spatial changes (Figs. 3a-c vs Figs. 1a-c) and changes in the seasonal cycle of the total sea ice area (blue and red curves, Fig. 3d). Specifically, a pronounced sea ice decline occurs in the East Siberian, Laptev, Kara, and Barents Seas (Fig. 3c). The sea ice area loss is minimal $(<10 \%)$ during boreal winter and maximal during boreal summer $(>30 \%$ in September). Even though a direct comparison with the recent decadal observations is limited, since the real ocean is still adjusting to any changes in the Arctic, these baseline experiments illustrate the relevant mechanisms that may already operate in nature in response to Arctic climate change.

Unlike the rapid Arctic sea ice change, the AMOC shows a delayed response in the SW and LW experiments. There is no robust AMOC weakening within the first 10-15 years of the simulations (red and blue curves, Fig. 4b) even right after the contraction of Arctic sea ice. However, from year 16 to about 100, the AMOC gradually weakens by $30 \%-40 \%$ ( $34 \%$ and $38 \%$ for the SW and LW experiments, respectively) and remains near constant afterward (again, except for natural internal variability). The mismatch between the long adjustment time scale for the AMOC and a much shorter time scale for Arctic sea ice is consistent with slow ocean adjustment to polar changes.

Our additional sensitivity experiments, in which we apply a stronger shortwave perturbation (Strong SW) or a weaker longwave perturbation (Weak LW), confirm that the induced Arctic sea ice loss is controlled by the strength of the imposed perturbation, while the resultant AMOC decline is proportional to the magnitude of the Arctic sea ice retreat (Fig. 4; Table 1).

\section{b. Physical mechanisms}

We will next focus on the SW experiment to explore in detail the physical mechanisms of how Arctic sea ice loss leads to the AMOC weakening. We have also analyzed the LW experiment (Figs. S3-S10) and found that the results are highly similar to the SW case (Figs. 5-12). The close similarity between the SW and LW experiments demonstrates that our results are robust and do not depend on a particular method used to modify the snow/sea ice radiation balance.

We begin with examining changes in surface density flux over the Arctic sea ice area during the first 80 years

(a) Arctic SIA

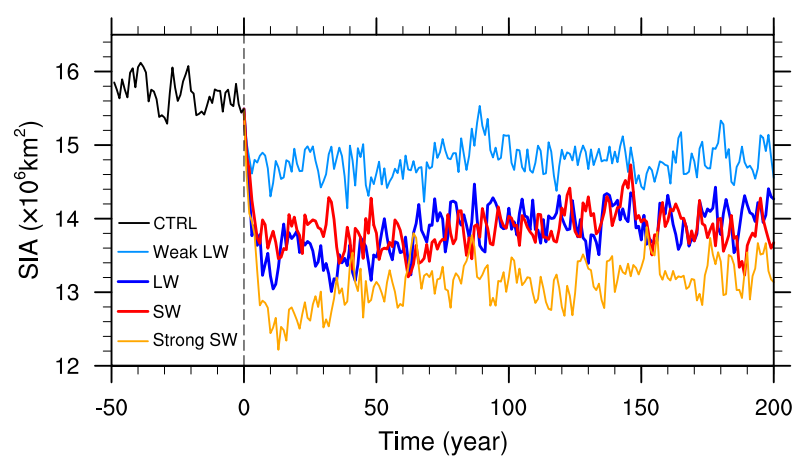

(b) AMOC

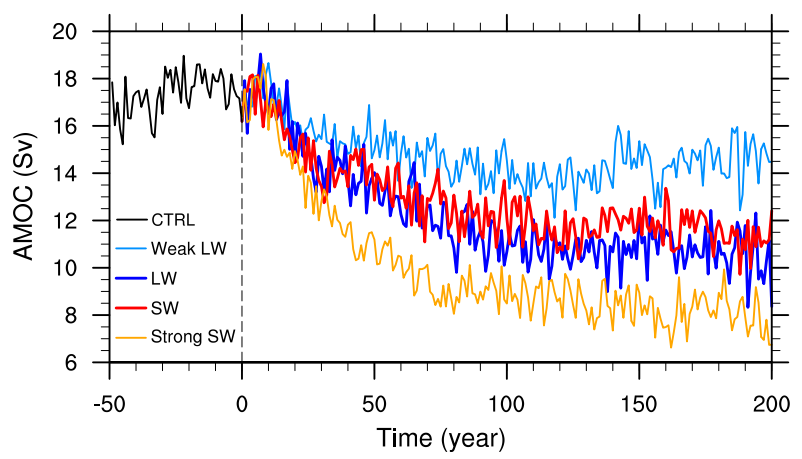

FIG. 4. (a) Annual mean Arctic SIA and (b) AMOC strength in the CTRL (black), Weak LW (light blue), LW (blue), SW (red), and Strong SW (orange) experiments. Perturbation experiments are initiated from the CTRL and set to start from time zero. The AMOC strength is defined as the maximum annual mean streamfunction in the North Atlantic below $500 \mathrm{~m}$. 
(a) $\Delta \mathrm{DF}$

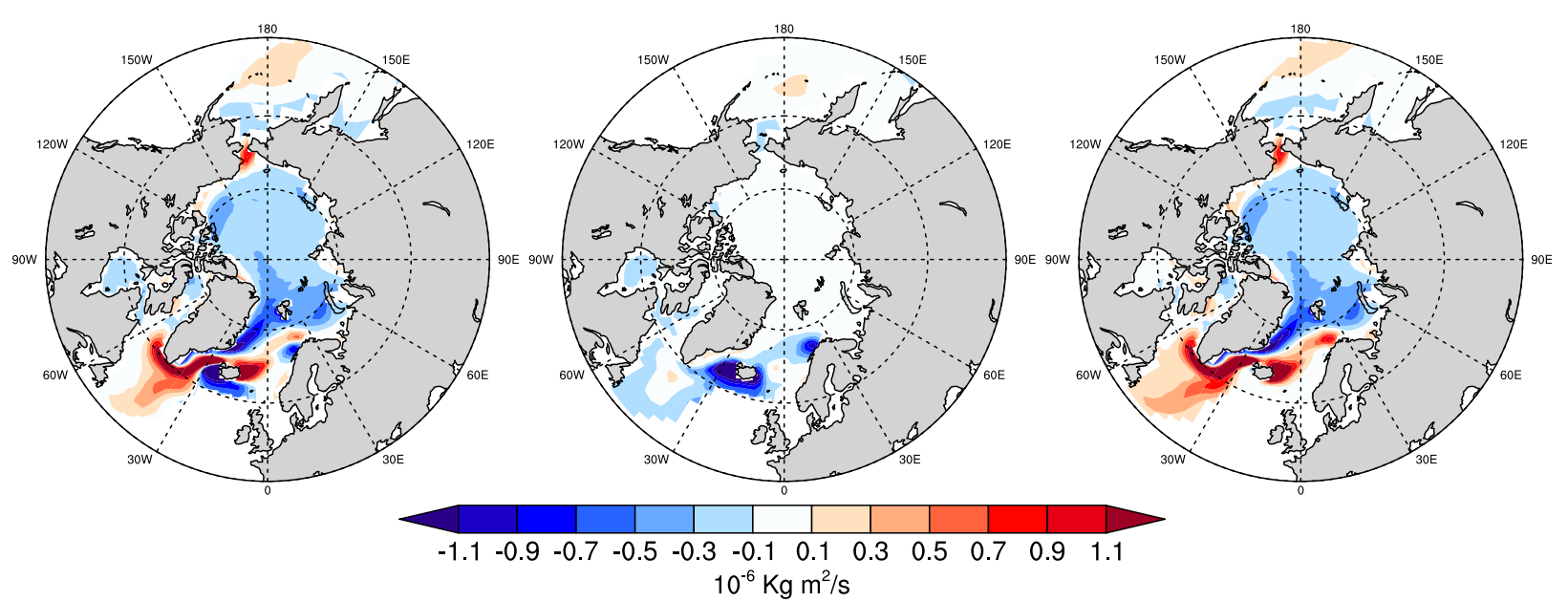

FIG. 5. Anomalies in (a) surface density flux (DF) and their (b) thermal (TF) and (c) haline (SF) components (color shading; $10^{-6} \mathrm{~kg} \mathrm{~m}^{2} \mathrm{~s}^{-1}$; positive downward) over the Arctic and subpolar regions averaged for the first 80 years of the SW experiment. Hereafter, anomalies are computed relative to a 50-yr mean of the CTRL.

of the SW experiment, which indicate the loss or gain of density of the ocean surface layer due to heat and freshwater exchanges (e.g., Schmitt et al. 1989; Liu et al. 2017). The density flux (DF) is calculated as

$$
\mathrm{DF}=-\alpha \frac{\mathrm{SHF}}{C_{p}}-\rho(0, \mathrm{SST}) \beta \frac{\mathrm{SFWF} \times \mathrm{SSS}}{1-\mathrm{SSS}},
$$

where $C_{p}$, SST, and SSS are specific heat capacity and sea surface temperature and salinity, respectively; $\alpha$ and $\beta$ are thermal expansion and haline contraction coefficients; and $\rho(0$, SST $)$ is density of freshwater with a salinity of 0 and the temperature of SST. SHF represents net surface heat flux into ocean (positive downward) computed as a sum of shortwave (sw) and longwave (lw) radiation, sensible $(\mathrm{SH})$ and latent $(\mathrm{LH})$ heat fluxes and heat fluxes from sea ice melting (Melt) and other minor sources. SFWF represents net surface freshwater flux into ocean (positive downward) computed as a sum of precipitation minus evaporation $(P-E)$, river runoff $(R)$, and freshwater fluxes from sea ice melting and brine rejection $(M-\mathrm{Br})$ and other sources. Accordingly, the first term $\left(-\alpha \mathrm{SHF} / C_{p}\right)$ represents the thermal contribution (denoted as TF) while the second term $[-\rho(0, \mathrm{SST}) \beta(\mathrm{SFWF} \times \mathrm{SSS}) /(1-\mathrm{SSS})]$ represents the haline contribution (denoted as SF) to the density flux.

We find that, in response to Arctic sea ice decline, negative density flux anomalies (i.e., positive buoyancy anomalies) are generated in most of the Arctic Ocean and around Iceland (Fig. 5a). Positive buoyancy anomalies over a large region of the Arctic Ocean mainly come from the haline contribution (Fig. 5c) as part of sea ice seasonal melting and freezing (Fig. 6h). If this process were strictly local, sea ice melting and brine rejection would compensate each other, resulting in a zero freshwater flux. However, there is a significant southward advection of (fresh) sea ice from this region. Consequently, when sea ice cover is reduced in summer, a greater fraction of sea ice has to be melted locally rather than being transported away. This leads to anomalous freshwater fluxes in perturbed experiments relative to the control simulation. In fact, changes in the seasonal melting of sea ice can produce about $0.2 \mathrm{~m} \mathrm{yr}^{-1}$ of anomalous freshwater into the ocean over the central area of the Arctic, and over $1.0 \mathrm{~m} \mathrm{yr}^{-1}$ in the Greenland Sea (Fig. 6h). At the same time, reduced advection from the north and hence reduced melting of sea ice induces negative freshwater flux anomalies (i.e., positive salinity anomalies) mainly in the regions south of Greenland and east of Iceland. It merits attention that precipitation minus evaporation (together with other freshwater flux components) shows a very small change (Fig. 6i) and therefore makes negligible contribution to the density flux anomalies and AMOC variations. This result, however, might be different in other models (Suo et al. 2017).

Positive buoyancy anomalies around Iceland and in the Norwegian Sea are primarily thermally controlled (Fig. 5b). During boreal summer, sea ice loss increases the area of open ocean (Fig. 3), inducing a strong anomalous solar heat flux into the ocean (Fig. 6b), as seawater has a much lower albedo than ice. This downward solar heat flux anomaly is partially compensated by anomalous longwave radiation from the surface (Fig. 6c). Sensible 
(a) $\triangle$ SHF

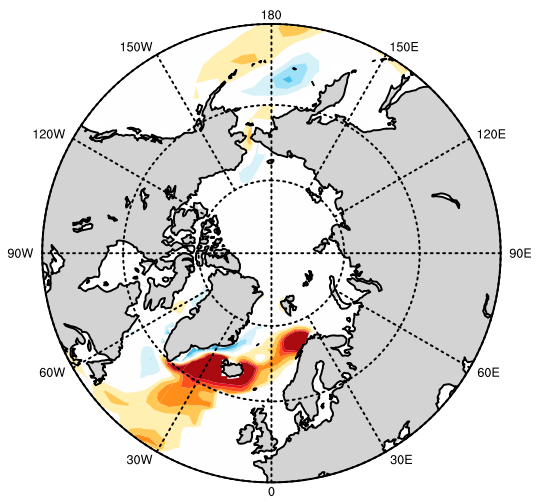

(d) $\Delta \mathrm{SH}$

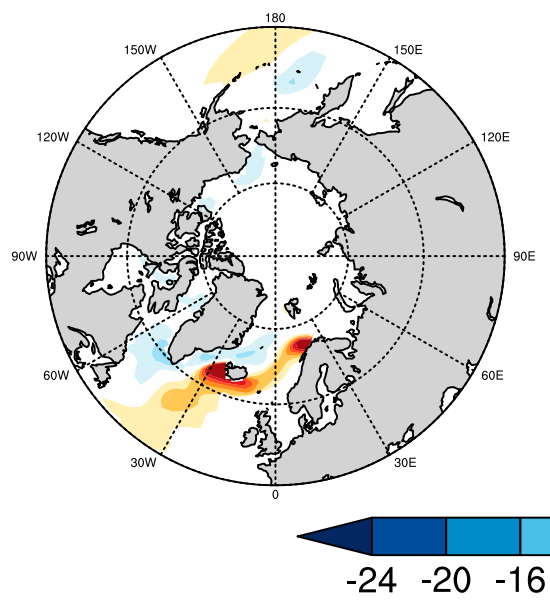

(g) $\triangle$ SFWF

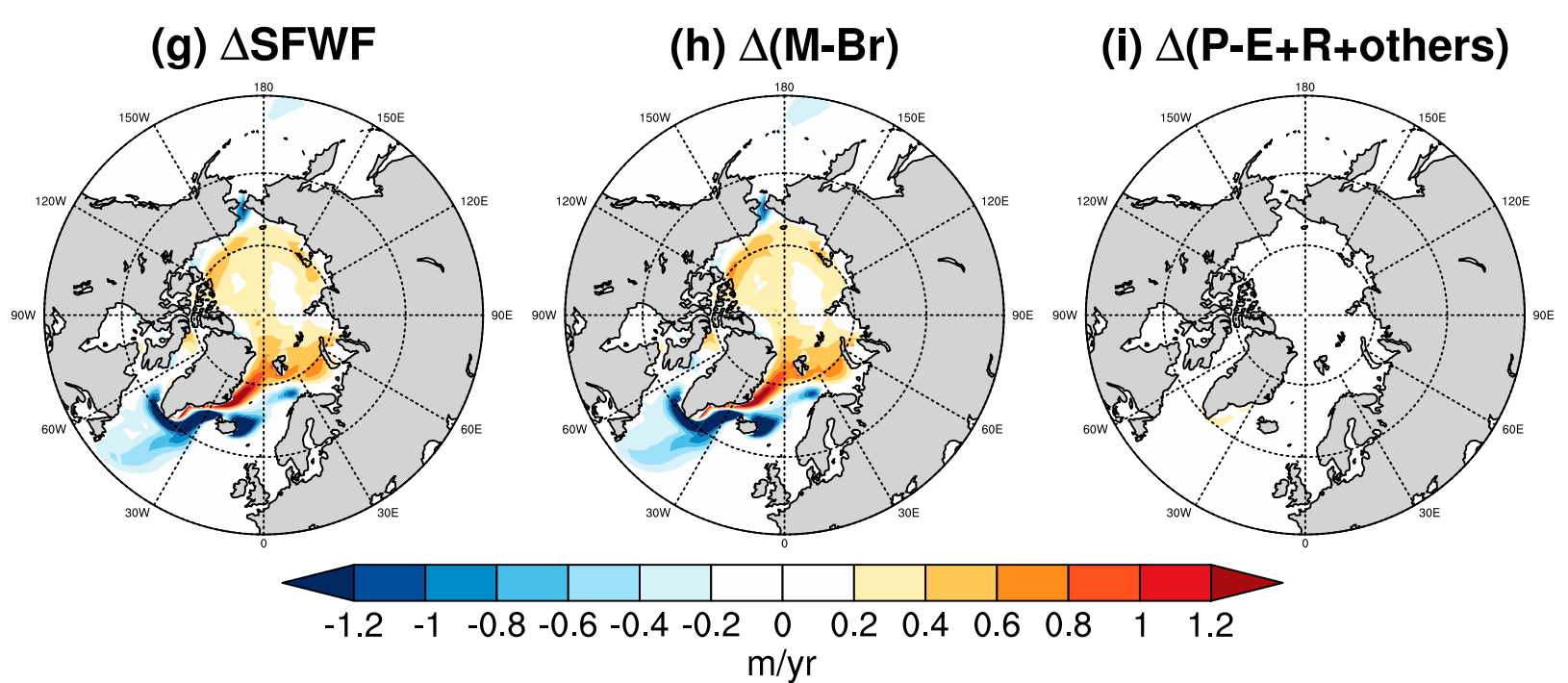

(b) $\Delta$ sw

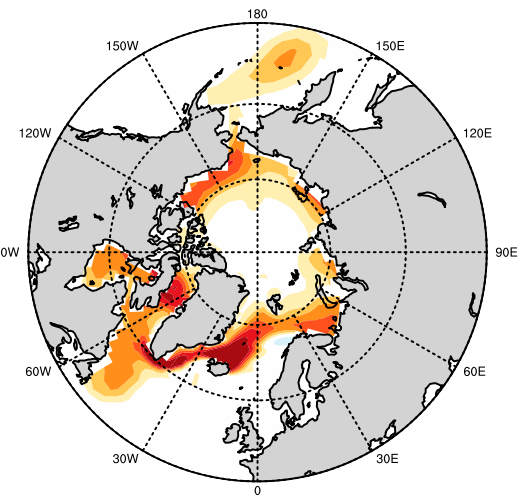

(e) $\Delta$ Melt
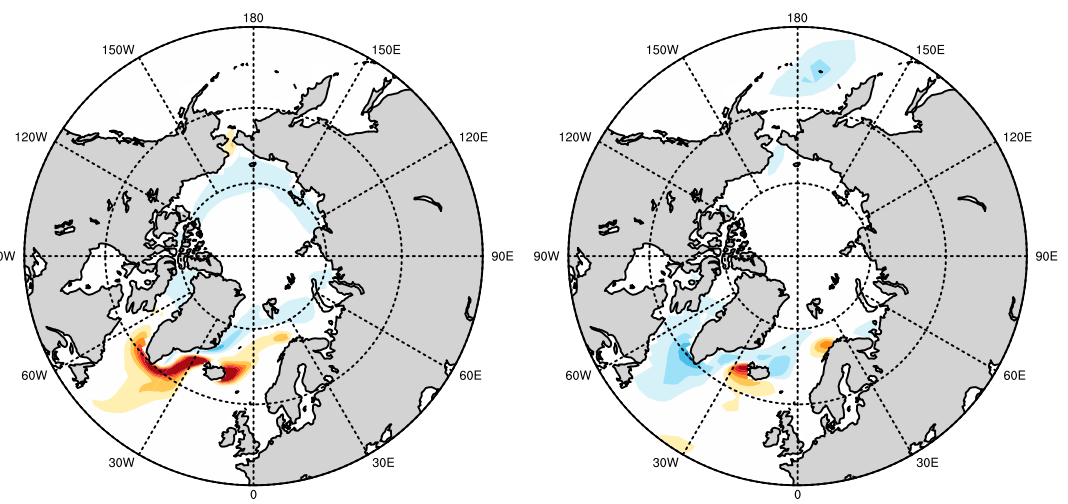

(c) $\Delta \mathrm{lw}$

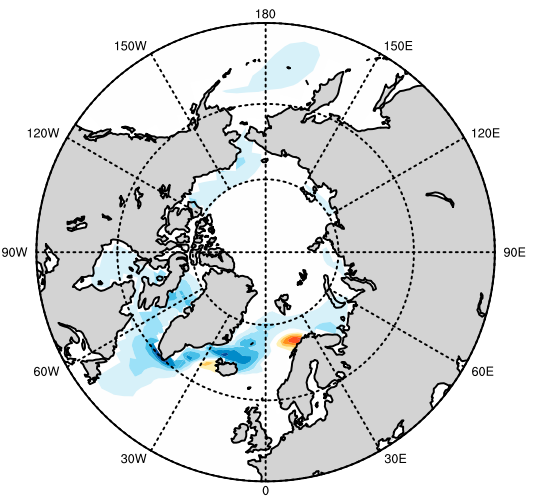

(f) $\Delta$ (LH+others)

FIG. 6. Anomalies over the first 80 years of the SW experiment for (a) total SHF, (b) sw, (c) lw, (d) SH, (e) $\Delta$ Melt, and (f) LH and other fluxes (color shading; $\mathrm{W} \mathrm{m}^{-2}$; positive downward), and for (g) total SFWF, (h) $M-\mathrm{Br}$, and (i) $P-E, R$, and other sources (color shading; $\mathrm{m} \mathrm{yr}^{-1}$; positive downward). Note that (a) and (g) are analogous to Figs. $5 \mathrm{~b}$ and $5 \mathrm{c}$, respectively. 
(a) $\Delta T(Y r$ 1-15)

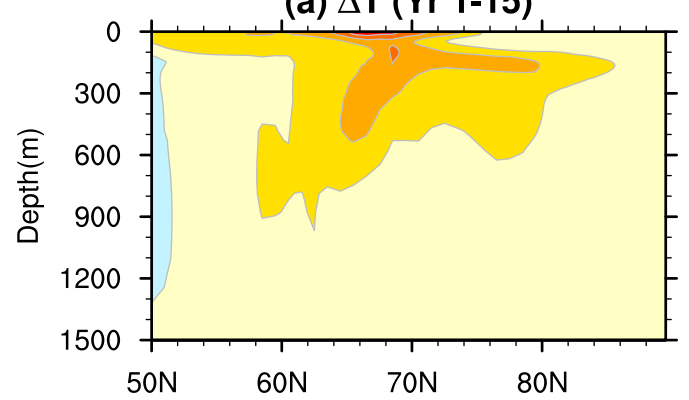

(c) $\Delta T(Y r$ 16-50)

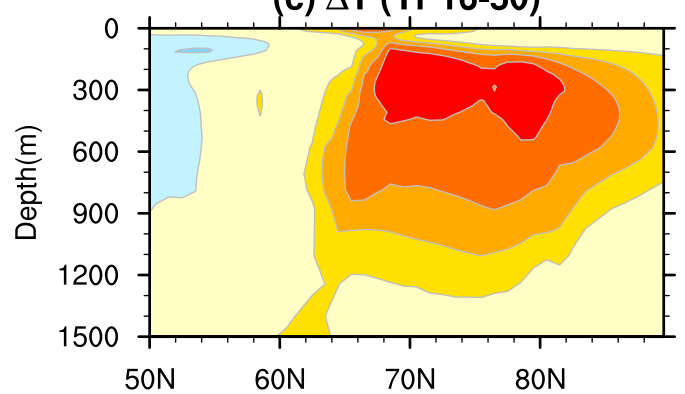

(e) $\Delta T(Y r$ 51-80)

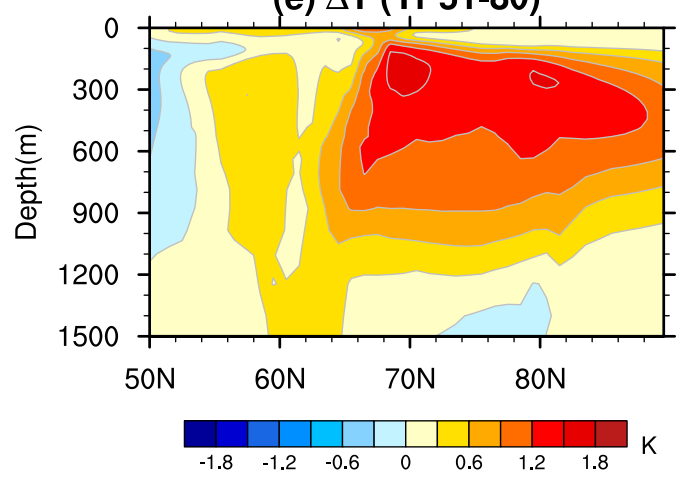

(b) $\Delta S$ (Yr 1-15)

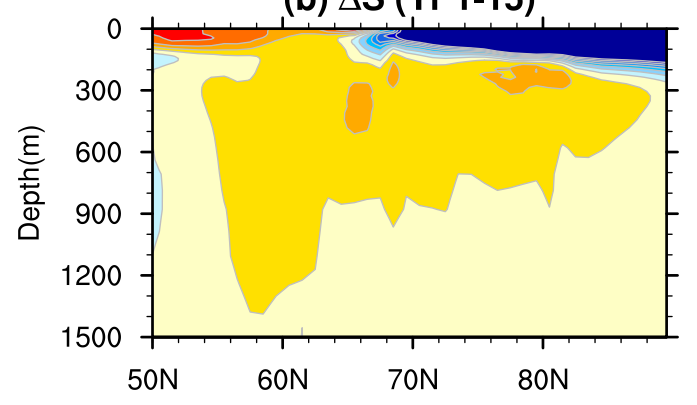

(d) $\Delta \mathrm{S}(\mathrm{Yr}$ 16-50)
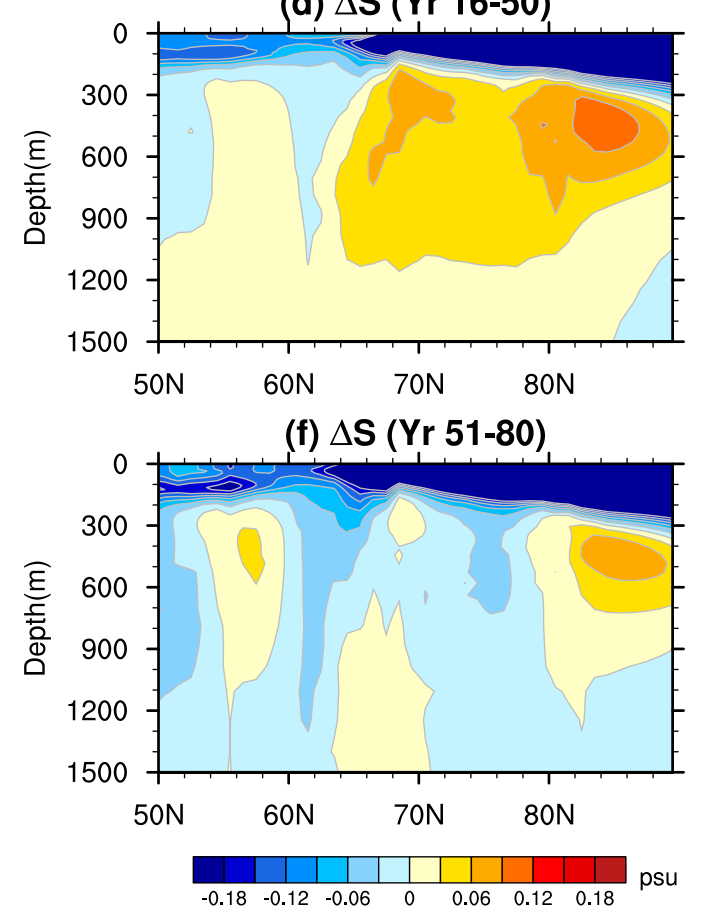

FIG. 7. Transects of (left) temperature (color shading; K) and (right) salinity (color shading; psu) showing anomalies averaged over $35^{\circ} \mathrm{W}-20^{\circ} \mathrm{E}$ (covering the region of deep convection) for years (a) 1-15, (c) $16-50$, and (e) 51-80 in the SW experiment.

and latent heat fluxes and the heat flux due to sea ice melting are also modified (Figs. $6 \mathrm{~d}-\mathrm{f}$ ). The combination of these different heat flux components generates a pattern of net anomalous heat flux into the ocean around Iceland and over the Norwegian Sea (Fig. 6a) and therefore positive buoyancy flux anomalies there (Fig. 5b).

On decadal and multidecadal time scales the induced buoyancy anomalies propagate southward as either temperature or salinity signals or both. As these anomalies arrive at deep convection areas (part of the temperature signal may be locally generated by anomalous surface heat flux over the deep convection areas), they can modify water density in the upper ocean and affect deep convection in the Nordic Seas and to the south of Iceland. The subsequent oceanic adjustments that involve Kelvin and large-scale Rossby waves modify ocean density structure and hence the AMOC across the basin (e.g., Kawase 1987; Huang et al. 2000; Johnson and Marshall 2002; Cessi et al. 2004; Zhang 2010; and more recently, Sévellec and Fedorov 2013; Sévellec and Fedorov 2015; Muir and Fedorov 2017; Germe et al. 2018). In particular, the signals are carried by Kelvin waves traveling equatorward along the western boundary, eastward across the equator, and poleward along the eastern boundary, and then by Rossby waves emanating from the eastern boundary to fill the interior of the Atlantic basin. Thus, the Arctic Ocean acts as a reservoir of positive buoyancy anomalies that sustain the weakening of the AMOC while spreading downstream from the Arctic into the North Atlantic. It is worth noting that subtropical AMOC variations are expected to lag deep convection variation by several 
(a) $\Delta \mathrm{T}(\mathrm{Yr}$ 1-15)

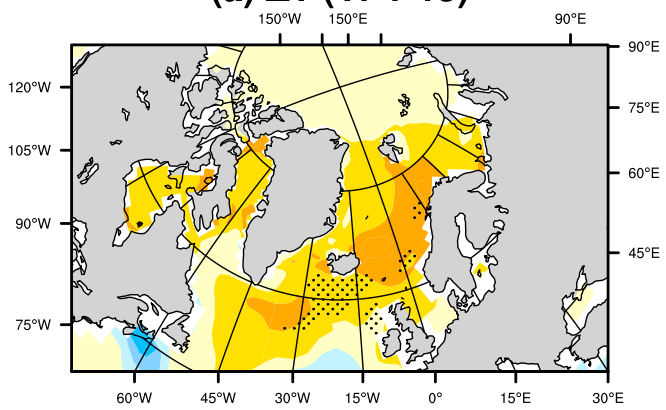

(c) $\Delta \mathrm{T}(\mathrm{Yr}$ 16-50)

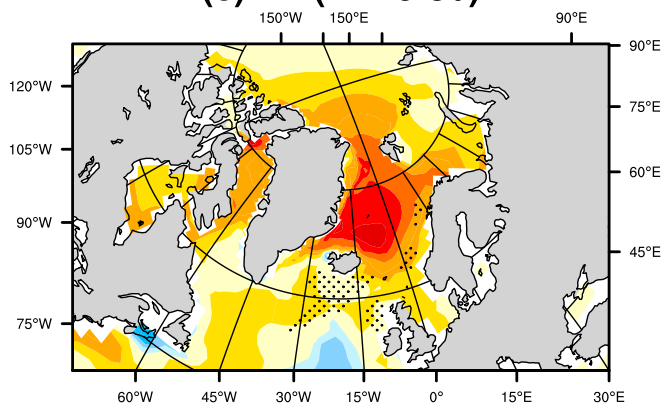

(e) $\Delta \mathrm{T}\left(\operatorname{Yr}_{10^{\circ} \mathrm{W}}\right.$ 51-80)

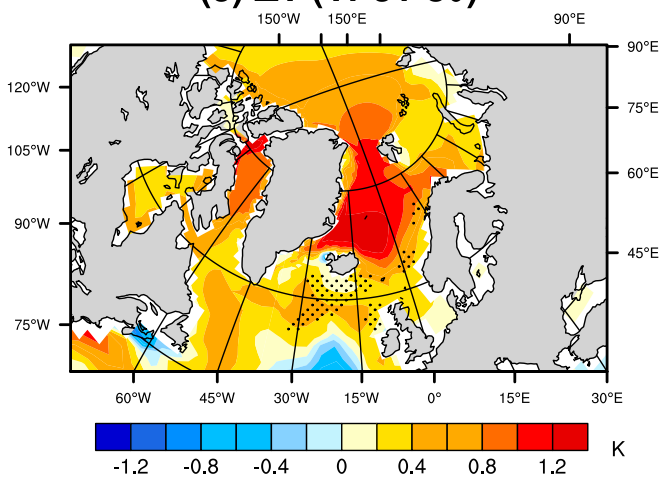

(b) $\Delta \mathrm{S}(\mathrm{Yr}$ 1-15)

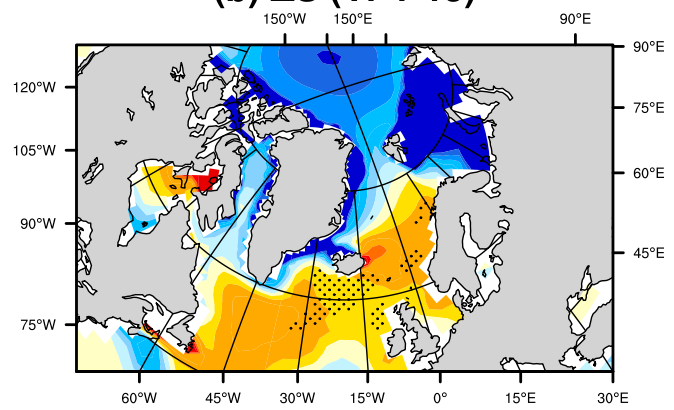

(d) $\Delta \mathrm{S}(\mathrm{Yr}$ 16-50)

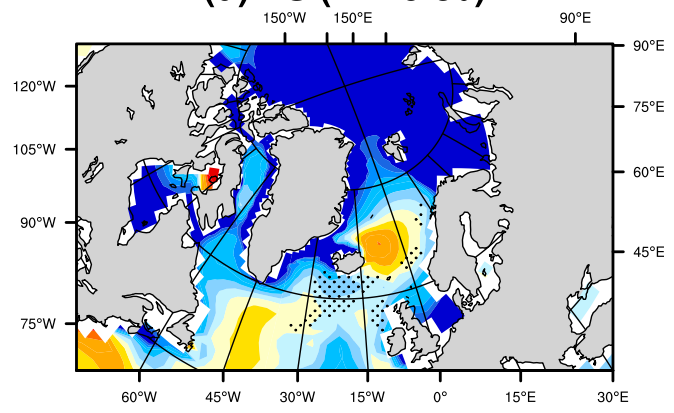

(f) $\underset{10^{\circ} \mathrm{W}}{\Delta \mathrm{S}}\left(\underset{10^{\circ} \mathrm{E}}{\mathbf{5 1}} \mathbf{5 1 - 8 0}\right)$

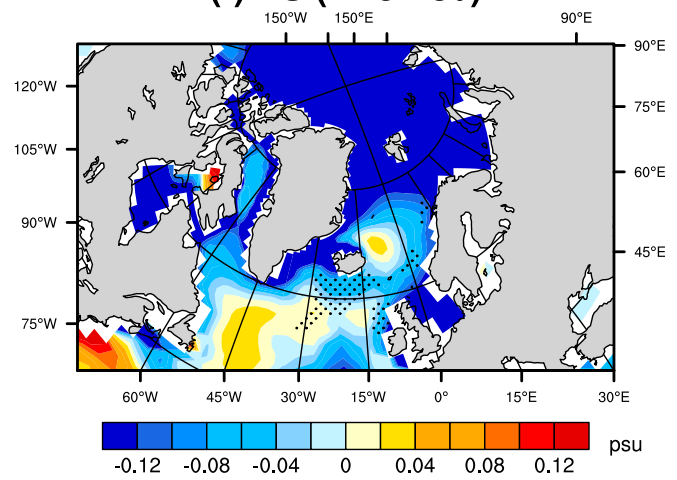

FIG. 8. Anomalies in (left) temperature (color shading; K) and (right) salinity (color shading; psu) averaged over the upper $1000 \mathrm{~m}$ for years (a) 1-15, (c) 16-50, and (e) 51-80 in the SW experiment. Deep convection regions are marked in each panel (defined where March MLD is greater than $400 \mathrm{~m}$; cf. Fig. 2b).

years due to the advection of the signals along the pathways of North Atlantic Deep Water and the induced wave propagation (Zhang 2010).

We find that the temperature and salinity signals exhibit distinct characteristics in their vertical structures, phases of propagation, and effects on density changes and hence AMOC variations. During the first 15 years, the freshening by sea ice melting is mostly confined to the upper $150 \mathrm{~m}$ in the Arctic Ocean and the Barents Sea (Fig. 7b) and close to Greenland (Fig. 8b), whereas the upper $1000 \mathrm{~m}$ of the deep convection region is affected by the warming (Fig. 8a) due to the positive heat flux anomaly around Iceland (Fig. 6a) and the increased salinity (Fig. 8b) due to the negative freshwater flux anomaly around Greenland (Fig. 6g). During this initial stage, the warming and increased salinity nearly compensate each other (Figs. 9a-c) and lead to a minimal change in upper ocean density in the southern part of the Nordic Sea and to the south of Iceland (Figs. 10a-c). As a result, deep convection over two key areas-one in the Norwegian Sea denoted as the "north" area and the other to the south of Iceland denoted as the "south" area-show few signs of inhibition (Fig. 11a), and the AMOC strength remains almost unchanged (Fig. 4b). An important effect is that the warming of the Arctic Ocean between 100 and $1200 \mathrm{~m}$ is largely compensated by the salinity increase. This warming of the Arctic Ocean originates in the Norwegian Sea (Fig. 8a). 
(a) $\Delta \rho_{\mathrm{T}}(\operatorname{Yr} 1-15)$

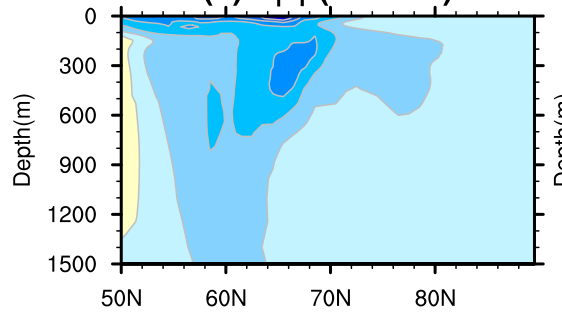

(d) $\Delta \rho_{\mathrm{T}}(\operatorname{Yr}$ 16-50)

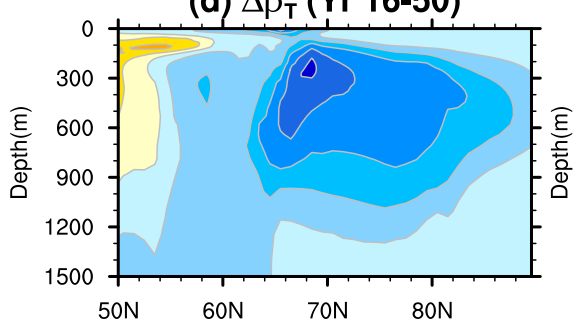

(g) $\Delta \rho_{\mathrm{T}}(\operatorname{Yr}$ 51-80)

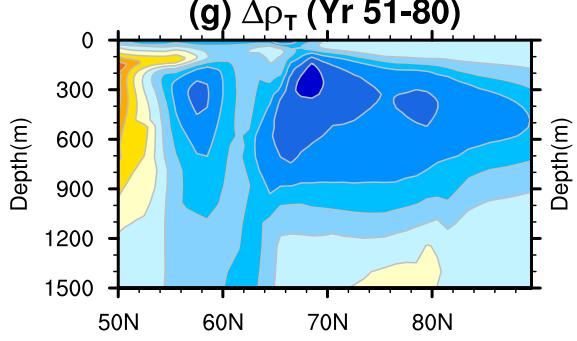

(b) $\Delta \rho_{s}(\operatorname{Yr}$ 1-15)

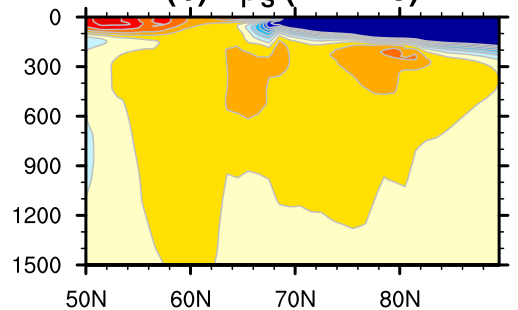

(e) $\Delta \rho_{s}(\operatorname{Yr} 16-50)$

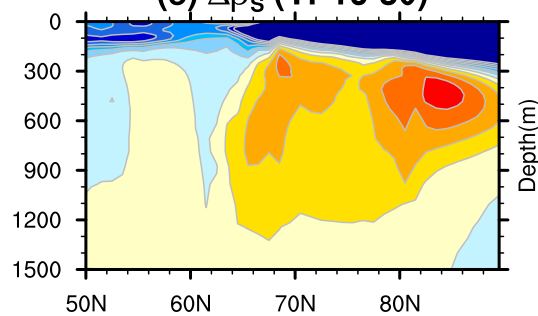

(h) $\Delta \rho_{s}($ Yr 51-80)

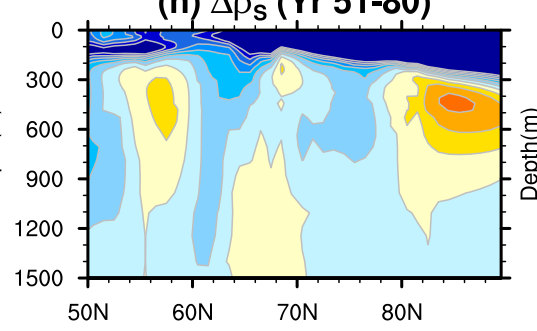

(c) $\Delta \rho(\operatorname{Yr} 1-15)$

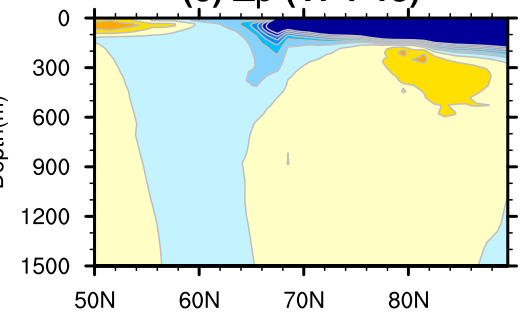

(f) $\Delta \rho(\operatorname{Yr} 16-50)$

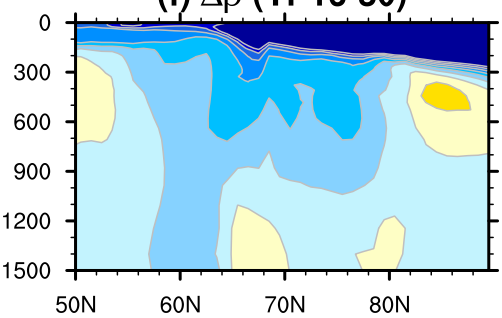

(i) $\Delta \rho(\operatorname{Yr} 51-80)$

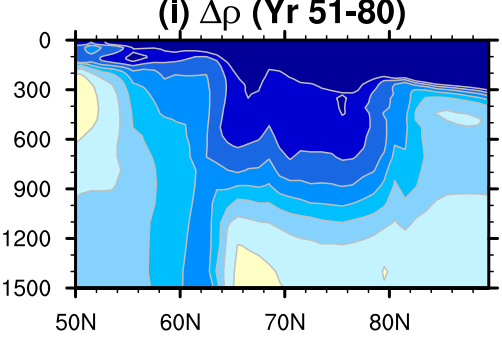

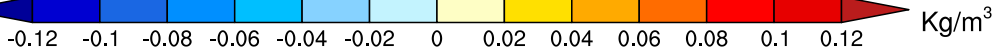

FIG. 9. As in Fig. 7, but for (right) density anomalies and their (left) thermal and (center) haline components (color shading; $\mathrm{kg} \mathrm{m}^{-3}$ ).

During years $16-50$, the freshening signal spreads southward and downward, eroding previous salinity anomalies and sweeping over the deep convection region (Figs. $7 \mathrm{~d}$ and $8 \mathrm{~d}$ ), whereas the warming strengthens over the Greenland Sea (Fig. 8c) and penetrates deeper, down to $1200 \mathrm{~m}$ (Fig. 7c). During this period, both freshening and warming contribute to a less dense upper-layer water over these so-called north and south areas (Figs. 9d-f and 10d-f). Deep convection in both areas is weakened (Figs. 11b,d,e), leading to a weaker AMOC (Fig. 4b). Over years 51-80, the warming and freshening anomalies propagate farther south (Figs. 7e,f and 8e,f) and act to reduce upper ocean density to the south of Iceland (Figs. 9g-i and $10 \mathrm{~g}-\mathrm{i})$. During this stage, deep convection in the north area remains nearly steady (Figs. 11c,d) while deep convection in the south area is suppressed even more (Figs. 11c,e). The latter effect leads to a further weakening of the AMOC (Fig. 4b).

To quantify the contributions of temperature and salinity anomalies to the change of upper ocean density and hence to the AMOC weakening, we decompose the density change $\Delta \rho$ into the thermal $\left(\Delta \rho_{T}\right.$, due to temperature) and haline ( $\Delta \rho_{S}$, due to salinity) components. We then average $\Delta \rho, \Delta \rho_{T}$, and $\Delta \rho_{S}$ horizontally over the north and south areas and vertically in the upper $1000 \mathrm{~m}$, and then estimate the anomalies relative to the control. We find that during the first 15 years of integration, $\Delta \rho_{T}=-0.04 \mathrm{~kg} \mathrm{~m}^{-3}, \Delta \rho_{S}=0.03 \mathrm{~kg} \mathrm{~m}^{-3}$, and $\Delta \rho=-0.01 \mathrm{~kg} \mathrm{~m}^{-3}$ in each area, which indicates that the thermal and haline contributions are opposite but almost equal in magnitude, thus leading to a minimal change in upper ocean density. As a result, there is no evident reduction in deep convection in either area (Figs. 11a,d,e) and hence in the strength of the AMOC (Fig. 4b). During the following century, we estimate $\Delta \rho_{T}=-0.06 \mathrm{~kg} \mathrm{~m}^{-3}$, $\Delta \rho_{S}=-0.09 \mathrm{~kg} \mathrm{~m}^{-3}$, and $\Delta \rho=-0.15 \mathrm{~kg} \mathrm{~m}^{-3}$ for the north area, while $\Delta \rho_{T}=-0.03 \mathrm{~kg} \mathrm{~m}^{-3}, \Delta \rho_{S}=-0.03 \mathrm{~kg} \mathrm{~m}^{-3}$, and $\Delta \rho=-0.06 \mathrm{~kg} \mathrm{~m}^{-3}$ for the south area. This means that both thermal and haline effects contribute to the reduction of upper ocean density, deep convection (Figs. 11b-e) and hence the AMOC strength (Fig. 4b), and the two effects have generally similar magnitudes. To summarize, the upper ocean warming plays the primary role in weakening the AMOC during the first $\sim 15$ years, after which freshwater from seasonal sea ice melting gradually spreads 
(a) $\Delta \rho_{150 \mathrm{~N}} \underset{1500^{\circ}}{(\mathrm{Yr} 1-15)}$

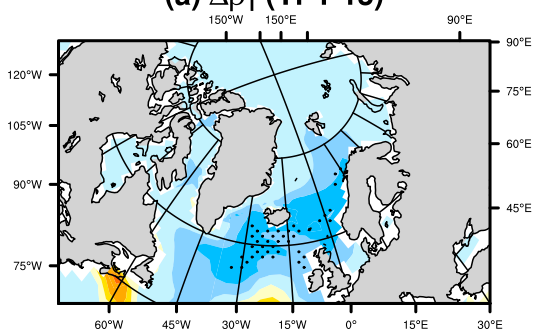

(d) $\Delta \rho_{\mathrm{T}}(\mathrm{Yr}$ 16-50)

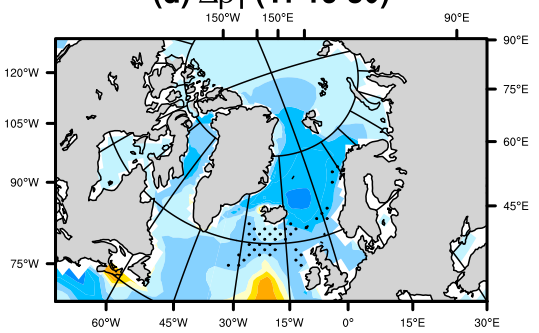

(g) $\Delta \rho_{\mathrm{T}}(\mathrm{Yr}$ 51-80)

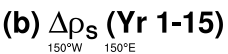

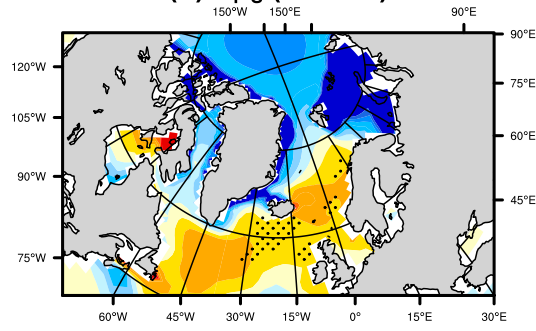

(e) $\Delta \rho_{S}(\operatorname{Yr} 16-50)$

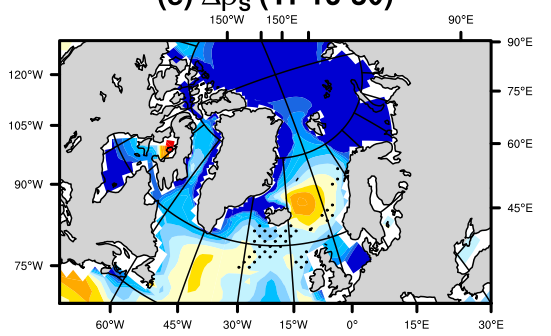

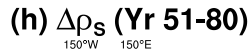
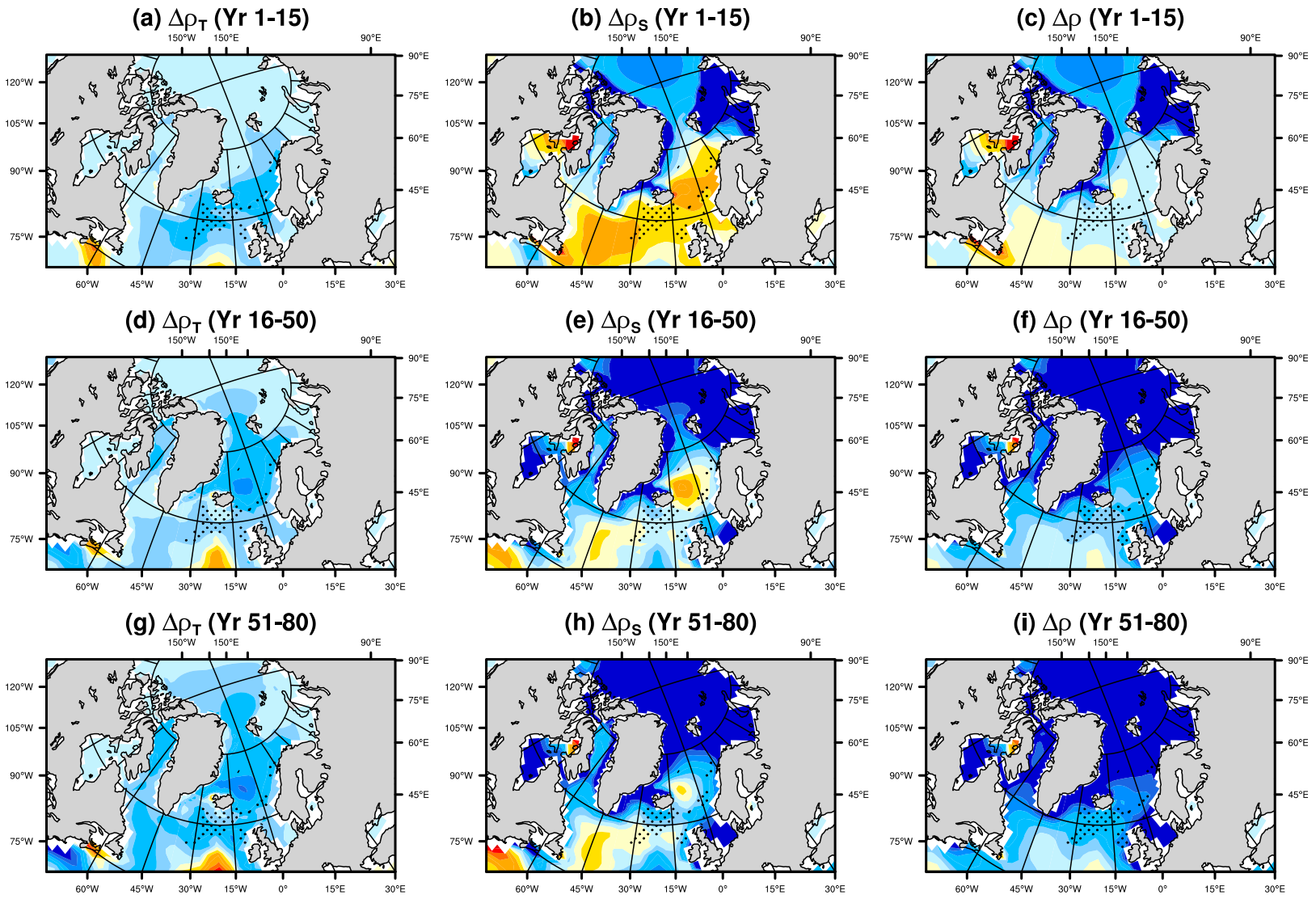

(f) $\Delta \rho(\operatorname{Yr} 16-50)$

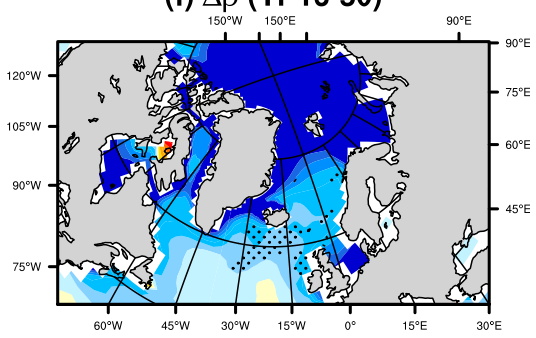

(i) $\underset{150^{\circ} \mathrm{W}}{\Delta 10^{\circ} \mathrm{E}}$ (Y1-80)

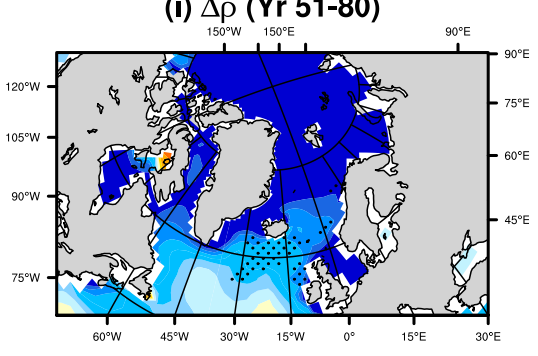

$\begin{array}{lllllllllllll}-0.12 & -0.1 & -0.08 & -0.06 & -0.04 & -0.02 & 0 & 0.02 & 0.04 & 0.06 & 0.08 & 0.1 & 0.12\end{array}$

FIG. 10. As in Fig. 8 but for (right) density anomalies and their (left) thermal and (center) haline components (color shading; in kg $\mathrm{m}^{-3}$ ).

over the subpolar North Atlantic and becomes as, or even slightly more, important.

Our other sensitivity experiments confirm that the induced Arctic sea ice loss is controlled by the strength of the imposed perturbation to the sea ice radiative budget, while the resultant AMOC decline is proportional to the magnitude of the Arctic sea ice retreat (Fig. 4, Table 1). This happens because, for example in the Strong SW experiment, a greater sea ice loss creates a larger area of open ocean, allowing greater heat absorption in the Arctic Ocean, while enhanced seasonal sea ice melting produces stronger freshwater anomalies. Both factors generate stronger positive buoyancy anomalies that spread into the subpolar North Atlantic as warming and freshening signals, leading to a greater reduction of upper ocean density over the deep convection region and therefore intensifying the AMOC decline.

\section{c. Subpolar freshwater budget}

Arctic sea ice decline induces a robust fast response in atmospheric circulation (e.g., Chiang and Bitz 2005;
Francis et al. 2009; Overland and Wang 2010; Screen et al. 2013; Deser et al. 2015). The corresponding surface wind change may influence the AMOC strength, either through freshwater/heat transport by winddriven gyre circulation (e.g., Timmermann and Goosse 2004) or through adjustment of the basin modes (e.g., Polo et al. 2014). To explore the wind effect, we first examine the change of surface wind stress over the Arctic and North Atlantic Oceans during the first 80 years of the SW experiment. We find that northward wind anomalies prevail in the central area of the Nordic Seas while southward wind anomalies prevail east of Greenland (Fig. 12a). The former anomalies help strengthen the West Spitsbergen Current and the latter help strengthen the East Greenland Current (Fig. 12b). At lower latitudes (e.g., at $\left.53^{\circ} \mathrm{N}\right)$, wind anomalies contribute to anomalous southward currents to the east of Canada and anomalous northwestward currents to the west of the British Isles (Fig. 12b). Nevertheless, it merits attention that Fig. 12b shows the total change of ocean currents, which also includes the 
(a) $\triangle M L D(\operatorname{Yr} 1-15)$

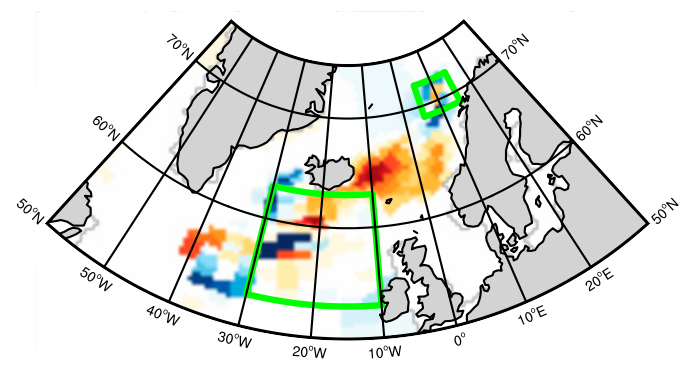

(b) $\triangle M L D(\operatorname{Yr~16-50)}$

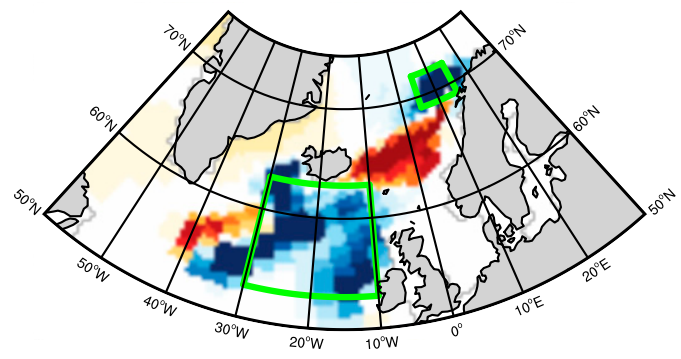

(c) $\triangle M L D(\operatorname{Yr} 51-80)$
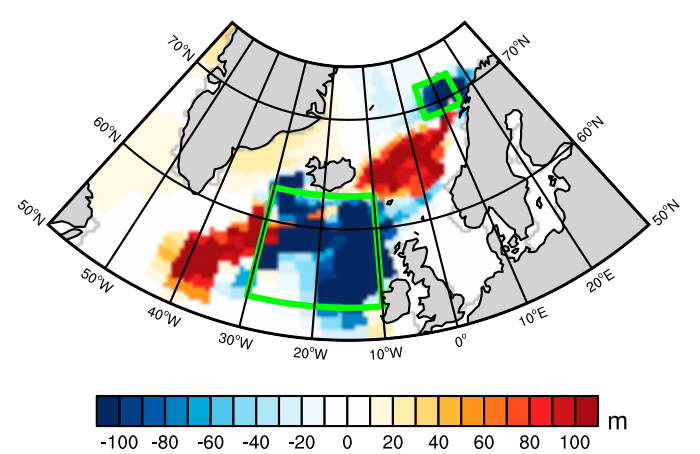

(d) $\triangle M L D$ evolution (north)

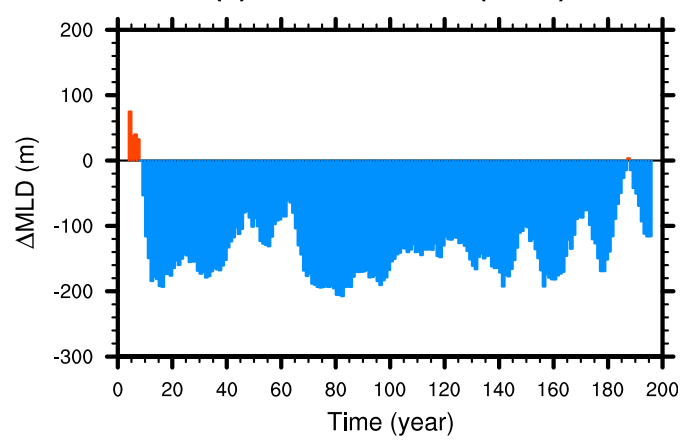

(e) $\triangle M L D$ evolution (south)

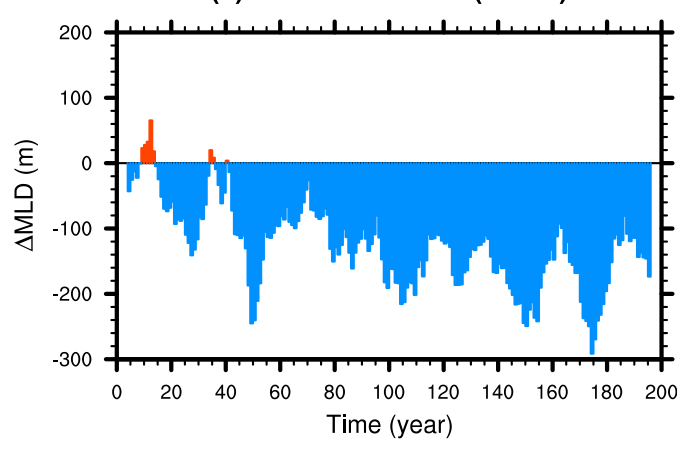

FIG. 11. (left) March MLD anomalies (color shading; K) over the North Atlantic for years (a) 1-15, (b) 16-50, and (c) 51-80 in the SW experiment. In (a)-(c), two key areas are denoted by green boxes: "north" $\left(69^{\circ}-72^{\circ} \mathrm{N}, 5^{\circ}-15^{\circ} \mathrm{E}\right)$ and "south" $\left(53^{\circ}-63^{\circ} \mathrm{N}, 10^{\circ}-30^{\circ} \mathrm{W}\right)$. (right) The evolution of March MLD anomalies averaged over these (d) north and (e) south boxes. A 9 -yr running mean is applied to reduce interannual variability.

part related to AMOC alterations (Timmermann and Goosse 2004).

A possible way to separate wind-driven circulation and the AMOC could be the experimental approach of Timmermann and Goosse (2004). However, such experiments are extensive and beyond the scope of this study (see also Fedorov et al. 2007). An alternative way is to consider freshwater budget over a confined region that covers all deep convection sites in the North Atlantic. The southern boundary of this region can be selected along $53^{\circ} \mathrm{N}$; the northern boundary, in the vicinity of $\sim 80^{\circ} \mathrm{N}$, separates the Arctic in the north along the Canadian Arctic Archipelago (CAA), Fram Strait, and the western shelf of the Barents Sea (Fig. 12b). We will analyze freshwater budget, rather than heat budget, because ocean circulation and temperature in the North
Atlantic are tightly coupled to each other (Marshall et al. 2015).

Since the oceanic component of the coupled model, POP2, uses a virtual salt flux instead of freshwater volume flux to represent freshwater exchange between the ocean and the atmosphere, freshwater in the budget is defined relative to a reference salinity $s_{0}$ of 34.8 psu. Oceanic freshwater transport across a section $M_{\mathrm{FW}}$ is defined as

$$
M_{\mathrm{FW}}=-\frac{1}{s_{0}} \iint v\left(s-s_{0}\right) d x d z
$$

and calculated from monthly model outputs. In Eq. (2), $v$ denotes the velocity along the normal direction of the section, $s$ is salinity of seawater, $x$ is the coordinate 
(a) $\left(\Delta \tau_{x}, \Delta \tau_{y}\right)$

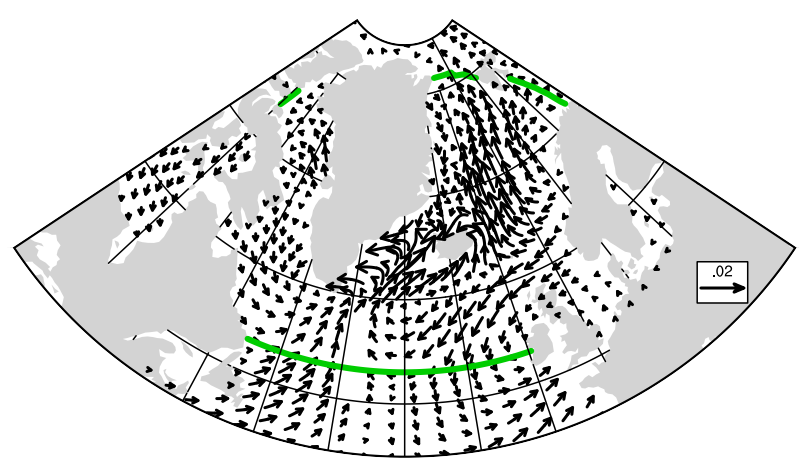

(b) $(\Delta U, \Delta V) \& S(C T R L)$

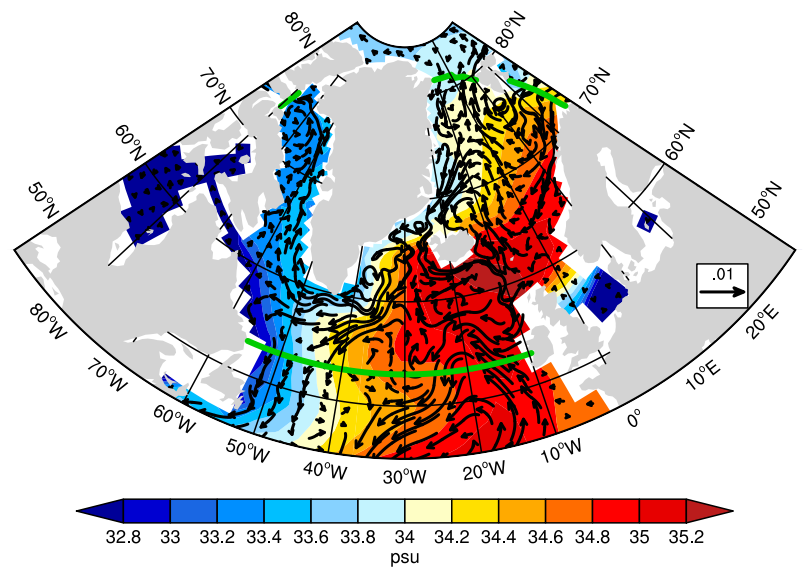

(c) $\Delta \mathrm{S} \&(\mathrm{U}, \mathrm{V})(\mathrm{CTRL})$

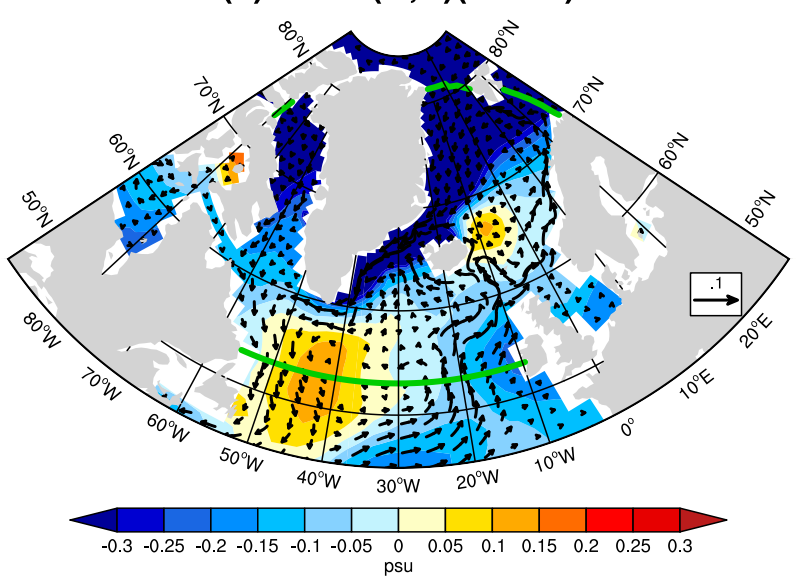

FIG. 12. Anomalies in (a) surface wind stress (vectors; $\mathrm{N} \mathrm{m}^{-2}$ ), (b) upper 200-m currents (vectors; $\mathrm{m} \mathrm{s}^{-1}$ ), and (c) upper 200-m salinity (psu; color shading) over the Arctic and North Atlantic averaged for the first 80 years of the SW experiment. Annual mean upper 200-m salinity (psu; color shading) and mean currents (vectors; $\mathrm{m} \mathrm{s}^{-1}$ ) from the CTRL are also shown in (b) and (c), respectively. The boundaries of the region selected for assessing freshwater budget are denoted by green curves.

along the direction of the section, and $z$ is along the vertical direction. Thereby, the freshwater budget can be written as

$$
\partial(\mathrm{FW}) / \partial t=F_{\mathrm{FW}}+M_{\mathrm{FWS}}-M_{\mathrm{FWN}}+D_{\mathrm{FW}},
$$

where $\partial(\mathrm{FW}) / \partial t$ denotes the tendency of vertically integrated freshwater in the region, $F_{\mathrm{FW}}$ denotes the SFWF (surface freshwater flux) integrated over the region surface and $D_{\mathrm{FW}}$ denotes the contribution from diffusion and mixing processes. Also, $M_{\mathrm{FWN}}$ denotes freshwater transport across the northern boundary, that is,

$$
M_{\mathrm{FWN}}=M_{\mathrm{FWFra}}+M_{\mathrm{FWBar}}+M_{\mathrm{FWCAA}},
$$

where $M_{\text {FWFra }}, M_{\text {FWBar }}$, and $M_{\text {FWCAA }}$ denote the freshwater transports across the Fram Strait, the western shelf of the Barents Sea and the CAA, respectively (Liu and Liu 2013, 2014; Liu et al. 2014); $M_{\text {Fws }}$ denotes meridional freshwater transport across $53^{\circ} \mathrm{N}$, which is mainly controlled by wind-driven gyre circulation and the AMOC. The gyre component $M_{\mathrm{FWG}}$ can be isolated via the following decomposition:

$$
M_{\mathrm{FWS}}=M_{\mathrm{FWG}}+M_{\mathrm{FWO}} \text {, }
$$

in which

$$
M_{\mathrm{FWG}}=-\frac{1}{s_{0}} \iint v^{*} s^{*} d x d z,
$$

where $v^{*}$ and $s^{*}$ denote the deviations of $v$ and $s$ from the their zonal means along the boundary (Rahmstorf 1996; Liu and Liu 2013). The term $M_{\text {FWO }}$ in Eq. (5) is primarily induced by the AMOC.

We explore the change in the freshwater budget [Eq. (3)] during the first 80 years of the SW experiment. The rate of change of freshwater in the selected region can be written as 


$$
\begin{aligned}
\partial(\mathrm{FW}) / \partial t= & \Delta F_{\mathrm{FW}}+\Delta M_{\mathrm{FWG}}+\Delta M_{\mathrm{FWO}} \\
& -\Delta M_{\mathrm{FWN}}+\Delta D_{\mathrm{FW}},
\end{aligned}
$$

where $\Delta(\cdot)$ represents the difference between the SW experiment and the CTRL. Here, $\partial(\mathrm{FW}) / \partial t$ specifies the freshwater tendency in the SW experiment, since the CTRL is in a quasi-equilibrium state so that $\partial(\mathrm{FW}) / \partial t \approx 0$. In particular, $\Delta M_{\mathrm{FWG}}$ can be modified by changes either in wind-driven gyre circulation or in salinity. To separate these two contributions, we decompose $\Delta M_{\mathrm{FWG}}$ as

$$
\Delta M_{\mathrm{FWG}}=\Delta M_{s \Delta v}+\Delta M_{v \Delta s}+\mathrm{Res},
$$

where $\Delta M_{s \Delta v}$ and $\Delta M_{v \Delta s}$ are calculated by fixing velocity and salinity at the climatological values in the CTRL, respectively. The term "Res" represents the residual part due to interannual/interdecadal variability of velocity and salinity and nonlinear terms due to velocity and salinity variations, which turns out to be negligible as compared to $\Delta M_{s \Delta v}$ and $\Delta M_{v \Delta s}$.

We first investigate the wind effect on freshwater budget by focusing on the term $\Delta M_{s \Delta v}$. Using Eqs. (6) and (8), we calculate that $\Delta M_{s \Delta v}=-0.009 \mathrm{~Sv}$; that is, the change of wind-driven gyre circulation acts to transport freshwater southward across $53^{\circ} \mathrm{N}$. As shown in Fig. 12b, the anomalous southward current to the east of Canada carries background low-salinity water while the anomalous northwestward current to the west of the British Isles carries background high-salinity water; both of them contribute to an anomalous southward freshwater transport. Nevertheless, the magnitude of $\Delta M_{s \Delta v}$ is much smaller than that of $\Delta M_{v \Delta s}$, the part from background circulation carrying salinity anomalies. As shown in Fig. 12c, the background currents transport positive salinity anomalies southward/southeastward to the east of Canada and negative salinity anomalies northward/northeastward to the west of the British Isles. Therefore, they generate an anomalous northward freshwater transport $\left(\Delta M_{v \Delta s}=0.022 \mathrm{~Sv}\right)$ across $53^{\circ} \mathrm{N}$, which overwhelms $\Delta M_{s \Delta v}$ and results in a net northward freshwater transport for the gyre component $\left(\Delta M_{\mathrm{FWG}}=0.013 \mathrm{~Sv}\right)$. To summarize, the wind change in response to sea ice loss acts to push freshwater away from the deep convection areas in the subpolar North Atlantic by altering the horizontal gyre circulation, which could potentially intensify the deep convection and the AMOC. However, this effect is overwhelmed by the effect due to the induced salinity change.

We further compare the changes in freshwater transport and surface freshwater flux and assess their roles in modulating oceanic deep convection and the AMOC. At the southern boundary, we calculate that
$\Delta M_{\mathrm{FWO}}=0.020 \mathrm{~Sv}$ and $\Delta M_{\mathrm{FWS}}=0.033 \mathrm{~Sv}$, which means that both gyre and AMOC components contribute to an anomalous northward freshwater transport across $53^{\circ} \mathrm{N}$. At the northern boundary, we find that $\Delta M_{\mathrm{FWN}}=-0.042 \mathrm{~Sv}$ and most of this anomalous Arctic freshwater import occurs through the Fram Strait and the Barents Sea $\left(\Delta M_{\text {FWFra }}=-0.015 \mathrm{~Sv}, \Delta M_{\mathrm{FWBar}}=-0.034 \mathrm{~Sv}\right.$, and $\left.\Delta M_{\mathrm{FWCAA}}=0.007 \mathrm{~Sv}\right)$ This result is consistent with the propagation of the freshening signals described in our previous analysis, and at the same time clarifies the path of propagation. Combining $\Delta M_{\mathrm{FWS}}$ and $\Delta M_{\mathrm{FWN}}$, we find an anomalous freshwater convergence of $0.075 \mathrm{~Sv}$ over the region. Meanwhile, we calculate that $\Delta F_{\mathrm{FW}}=-0.061 \mathrm{~Sv}$; that is, freshwater is locally removed from the region via the ocean surface (Fig. $6 \mathrm{~g}$ ). Thus, we conclude that the anomalous freshwater convergence, rather than surface freshwater flux change, serves as the main factor of the upper ocean freshening that weakens deep convection and the AMOC. Here, it is worth noting that Suo et al. (2017) also found a wind change effect on the AMOC weakening but via a different mechanism, which could be due to a different model and/or approach used.

\section{Discussion and conclusions}

In this study, we have examined the mechanisms by which Arctic sea ice loss induces the weakening of the AMOC within a fully coupled climate model. To exclude the anthropogenic warming effects and isolate the direct effect of sea ice decline, we perturb only the radiative properties of Arctic sea ice in a way that allows for a greater shortwave absorption or weaker longwave emission at the ice surface. We find that Arctic sea ice rapidly retreats after such perturbations, whereas the AMOC stays fairly constant within the first 15 years but then gradually slows down until around year 100. This two-stage AMOC response is related to the gradual southward propagation of buoyancy anomalies induced by sea ice decline. During the first 1-2 decades of integration, warming by positive heat flux anomalies around Iceland and salinity increase due to negative freshwater flux anomalies around Greenland mostly compensate each other over the deep convection region, leading to a minimal change of upper ocean density and hence the AMOC. However, on multidecadal time scales, warm water accumulates and propagates southward to the subpolar North Atlantic, and at the same time freshwater generated by sea ice melting in the central Arctic Ocean also propagates southward and sweeps over the deep convection region. These warming and freshening effects almost equally contribute to the decrease of upper ocean density in the subpolar North Atlantic, and 
hence to the suppression of deep convection and the AMOC slowdown.

We have also explored the effect of surface wind change on AMOC variations via a freshwater budget analysis. We find that the change of wind-driven gyre circulation acts to push freshwater away from the deep convection areas in the subpolar North Atlantic, which could potentially intensify deep convection and the AMOC. However, this wind effect is weak in comparison with other factors.

Our results also show a negative feedback of the AMOC on Arctic sea ice reported in previous studies (e.g., Mahajan et al. 2011; Day et al. 2012; Zhang 2015). It has been suggested that the AMOC can affect Arctic sea ice through its poleward heat transport. For example, a reduction in the AMOC and associated heat transport can cool high-latitude sea surface temperature leading to the growth of sea ice cover. We see this negative feedback relatively clear in our strongest perturbation experiment (Strong SW) as there are weak opposite trends in Arctic sea ice and AMOC strength during the AMOC decline phase (this feedback is still present in the weaker perturbation experiments but is harder to identify due to internal variability). Specifically, in the Strong SW experiment the AMOC declines at a rate of $-0.9 \mathrm{~Sv}$ per decade during years 16-80 (Fig. 4b), which causes a reduction of ocean heat transport in the Atlantic across $60^{\circ} \mathrm{N}$ at a rate of $-0.5 \times 10^{-2} \mathrm{PW}$ per decade and a slight increase of Arctic sea ice area at a rate of $0.1 \times 10^{6} \mathrm{~km}^{2}$ per decade (Fig. 4a). It merits attention that the imposed perturbation in snow/ice radiative properties is kept constant throughout our experiments and is the dominant factor controlling the Arctic sea ice loss. The negative feedback from the AMOC decline leads to a small sea ice recovery during ocean adjustment but remains of secondary importance in the experiments (Fig. 4a).

In addition, we have compared deep convection sites in the observations (Fig. 2a) and 12 CMIP5 models (Fig. S1) including the CESM family models (CCSM4, CESM1-BGC, and CESM1-CAM5) to explore possible factors affecting the $\sim 100$-yr time scale found in this study. This time scale is given by the period needed for the sea ice-induced buoyancy anomalies to accumulate, then to reach the deep convection areas and modulate the AMOC, and then for the circulation to approach a relatively steady state through basin adjustment (the time needed for the first signal reaching the deep convection sites could be within decades, but approaching a relatively steady state requires $\sim 100$ years). Given large intermodel differences in deep convection in the North Atlantic (Fig. S1; also see Heuzé 2017; Menary and Wood 2018), the time scale could be model dependent. For example, for models with deep convection sites in the Nordic Seas (such as CESM1_T31_gx3v7), the Greenland-Iceland Ridge and Faroe Bank Channel overflows could play important roles. For models with deep convection sites in the Labrador Sea (e.g., for the $1^{\circ}$ CESM family models), advection by the East Greenland Current through the Denmark Strait could be important (Sévellec and Fedorov 2015; Sévellec et al. 2017). However, the time scales between the two cases are hard to compare without direct experiments. On the one hand, the deep convection site south of Iceland provides a shortcut for the propagation of the Arctic signal. On the other hand, the East Greenland Current is relatively swift in carrying the Arctic signal but the distance toward the Labrador Sea is longer. Moreover, the subsequent ocean adjustment can be different in the two cases. Therefore, how effective the proposed mechanism is for weakening the AMOC still needs to be tested with other models.

Acknowledgments. This work was supported by grants to WL by the Regents' Faculty Fellowship, to AF from the DOE Office of Science (DE-SC0016538) and NSF (OCE-1756682, OPP-1741841) and by the Guggenheim Fellowship, and to FS from Natural and Environmental Research Council UK (SMURPHS, NE/N005767/1) and by the DECLIC project funded through the French CNRS/INSU/LEFE program.

\section{REFERENCES}

Bakker, P., and Coauthors, 2016: Fate of the Atlantic meridional overturning circulation: Strong decline under continued warming and Greenland melting. Geophys. Res. Lett., 43, 12 252-12 260, https://doi.org/10.1002/2016GL070457.

Bitz, C. M., P. R. Gent, R. A. Woodgate, M. M. Holland, and R. Lindsay, 2006: The influence of sea ice on ocean heat uptake in response to increasing $\mathrm{CO}_{2}$. J. Climate, 19, 2437-2450, https://doi.org/10.1175/JCLI3756.1.

Blackport, R., and P. J. Kushner, 2016: The transient and equilibrium climate response to rapid summertime sea ice loss in CCSM4. J. Climate, 29, 401-417, https://doi.org/10.1175/ JCLI-D-15-0284.1.

— , and - 2017: Isolating the atmospheric circulation response to Arctic sea ice loss in the coupled climate system. J. Climate, 30, 2163-2185, https://doi.org/10.1175/ JCLI-D-16-0257.1.

Caesar, L., S. Rahmstorf, A. Robinson, G. Feulner, and V. Saba, 2018: Observed fingerprint of a weakening Atlantic Ocean overturning circulation. Nature, 556, 191-196, https://doi.org/ 10.1038/s41586-018-0006-5.

Cessi, P., K. Bryan, and R. Zhang, 2004: Global seiching of thermocline waters between the Atlantic and the Indian-Pacific Ocean basins. Geophys. Res. Lett., 31, L04302, https://doi.org/ 10.1029/2003GL019091.

Chiang, J. C. H., and C. M. Bitz, 2005: Influence of high latitude ice cover on the marine intertropical convergence zone. Climate Dyn., 25, 477-496, https://doi.org/10.1007/ s00382-005-0040-5. 
Cvijanovic, I., B. D. Santer, C. Bonfils, D. D. Lucas, J. C. H. Chiang, and S. Zimmerman, 2017: Future loss of Arctic sea-ice cover could drive a substantial decrease in California's rainfall. Nat. Commun., 8, 1947, https://doi.org/10.1038/s41467-017-01907-4.

Day, J. J., J. C. Hargreaves, J. D. Annan, and A. Abe-Ouchi, 2012: Sources of multi-decadal variability in Arctic sea ice extent. Environ. Res. Lett., 7, 034011, https://doi.org/10.1088/1748-9326/ 7/3/034011.

Delworth, T. L., S. Manabe, and R. J. Stouffer, 1997: Multidecadal climate variability in the Greenland Sea and surrounding regions: A coupled model simulation. Geophys. Res. Lett., 24, 257-260, https://doi.org/10.1029/96GL03927.

Deser, C., R. A. Tomas, and L. Sun, 2015: The role of oceanatmosphere coupling in the zonal-mean atmospheric response to Arctic sea ice loss. J. Climate, 28, 2168-2186, https://doi.org/ 10.1175/JCLI-D-14-00325.1.

Dickson, R. R., J. Meincke, S.-A. Malmberg, and A. J. Lee, 1988: The "great salinity anomaly" in the northern North Atlantic 1968-1982. Prog. Oceanogr., 20, 103-151, https://doi.org/ 10.1016/0079-6611(88)90049-3.

Ding, Q., and Coauthors, 2017: Influence of high-latitude atmospheric circulation changes on summertime Arctic sea ice. Nat. Climate Change, 7, 289-295, https://doi.org/10.1038/ nclimate 3241 .

Eisenman, I., T. Schneider, D. S. Battisti, and C. M. Bitz, 2011: Consistent changes in the sea ice seasonal cycle in response to global warming. J. Climate, 24, 5325-5335, https://doi.org/ 10.1175/2011JCLI4051.1.

Fedorov, A., M. Barreiro, G. Boccaletti, R. Pacanowski, and S. G. Philander, 2007: The freshening of surface waters in high latitudes: Effects on the thermohaline and wind-driven circulations. J. Phys. Oceanogr., 37, 896-907, https://doi.org/10.1175/ JPO3033.1.

Francis, J. A., W. Chan, D. J. Leathers, J. R. Miller, and D. E. Veron, 2009: Winter Northern Hemisphere weather patterns remember summer Arctic sea-ice extent. Geophys. Res. Lett., 36, L07503, https://doi.org/10.1029/2009GL037274.

Germe, A., F. Sévellec, J. Mignot, A. Fedorov, S. Nguyen, and D. Swingedouw, 2018: The impacts of oceanic deep temperature perturbations in the North Atlantic on decadal climate variability and predictability. Climate Dyn., 51, 2341-2357, https://doi.org/10.1007/s00382-017-4016-z.

Gervais, M., J. Shaman, and Y. Kushnir, 2018: Mechanisms governing the development of the North Atlantic warming hole in the CESM-LE future climate simulations. J. Climate, 31, 5927-5946, https://doi.org/10.1175/JCLI-D-17-0635.1.

Graversen, R. G., and M. Wang, 2009: Polar amplification in a coupled climate model with locked albedo. Climate Dyn., 33, 629-643, https://doi.org/10.1007/s00382-009-0535-6.

Gregory, J. M., and Coauthors, 2005: A model intercomparison of changes in the Atlantic thermohaline circulation in response to increasing atmospheric $\mathrm{CO}_{2}$ concentration. Geophys. Res. Lett., 32, L12703, https://doi.org/10.1029/2005GL023209.

Häkkinen, S., 1993: An Arctic source for the Great Salinity Anomaly: A simulation of the Arctic ice-ocean system for 1955-1975. J. Geophys. Res., 98, 16397-16410, https://doi.org/ 10.1029/93JC01504.

, 1999: A simulation of thermohaline effects of a Great Salinity Anomaly. J. Climate, 12, 1781-1795, https://doi.org/10.1175/ 1520-0442(1999)012<1781:ASOTEO > 2.0.CO;2.

Heuzé, C., 2017: North Atlantic deep water formation and AMOC in CMIP5 models. Ocean Sci., 13, 609-622, https://doi.org/ 10.5194/os-13-609-2017.
Holland, M. M., D. A. Bailey, B. P. Briegleb, B. Light, and E. Hunke, 2012: Improved sea ice shortwave radiation physics in CCSM4: The impact of melt ponds and aerosols on Arctic sea ice. J. Climate, 25, 1413-1430, https://doi.org/10.1175/ JCLI-D-11-00078.1.

Hu, A., G. A. Meehl, W. M. Washington, and A. Dai, 2004: Response of the Atlantic thermohaline circulation to increased atmospheric $\mathrm{CO}_{2}$ in a coupled model. J. Climate, 17, 42674279, https://doi.org/10.1175/JCLI3208.1.

— B. L. Otto-Bliesner, G. A. Meehl, W. Han, C. Morrill, E. C. Brady, and B. Briegleb, 2008: Response of thermohaline circulation to freshwater forcing under present-day and LGM conditions. J. Climate, 21, 2239-2258, https://doi.org/10.1175/ 2007JCLI1985.1.

_ G. A. Meehl, W. Han, and J. Yin, 2009: Transient response of the MOC and climate to potential melting of the Greenland Ice Sheet in the 21st century. Geophys. Res. Lett., 36, L10707, https://doi.org/10.1029/2009GL037998.

$\longrightarrow,-,-$, J. Lu, and W. G. Strand, 2013: Energy balance in a warm world without the ocean conveyor belt and sea ice. Geophys. Res. Lett., 40, 6242-6246, https://doi.org/10.1002/ 2013 GL058123.

Huang, R. X., M. A. Cane, N. Naik, and P. Goodman, 2000: Global adjustment of the thermocline in response to deepwater formation. Geophys. Res. Lett., 27, 759-762, https://doi.org/ 10.1029/1999GL002365.

Jahn, A., and M. M. Holland, 2013: Implications of Arctic sea ice changes for North Atlantic deep convection and the meridional overturning circulation in CCSM4-CMIP5 simulations. Geophys. Res. Lett., 40, 1206-1211, https://doi.org/10.1002/ grl.50183.

Johnson, H. L., and D. P. Marshall, 2002: A theory for the surface Atlantic response to thermohaline variability. J. Phys. Oceanogr., 32,1121-1132, https://doi.org/10.1175/1520-0485(2002) 032<1121:ATFTSA $>2.0$. CO;2.

Jungclaus, J. H., H. Haak, M. Latif, and U. Mikolajewicz, 2005: Arctic-North Atlantic interactions and multidecadal variability of the meridional overturning circulation. J. Climate, 18, 4013-4031, https://doi.org/10.1175/JCLI3462.1.

——, - M. Esch, E. Roeckner, and J. Marotzke, 2006: Will Greenland melting halt the thermohaline circulation? Geophys. Res. Lett., 33, L17708, https://doi.org/10.1029/ 2006GL026815.

Kawase, M., 1987: Establishment of deep ocean circulation driven by deep-water production. J. Phys. Oceanogr., 17, 2294-2317, https://doi.org/10.1175/1520-0485(1987)017<2294: EODOCD $>2.0 . \mathrm{CO} ; 2$

Lawrence, D. M., K. W. Oleson, M. G. Flanner, C. G. Fletcher, P. J Lawrence, S. Levis, S. C. Swenson, and G. B. Bonan, 2012: The CCSM4 land simulation, 1850-2005: Assessment of surface climate and new capabilities. J. Climate, 25, 2240-2260, https:// doi.org/10.1175/JCLI-D-11-00103.1.

Levermann, A., J. Mignot, S. Nawrath, and S. Rahmstorf, 2007: The role of northern sea ice cover for the weakening of the thermohaline circulation under global warming. J. Climate, 20, 4160-4171, https://doi.org/10.1175/JCLI4232.1.

Liu, W., and Z. Liu, 2013: A diagnostic indicator of the stability of the Atlantic meridional overturning circulation in CCSM3. J. Climate, 26, 1926-1938, https://doi.org/10.1175/ JCLI-D-11-00681.1.

— , and - 2014: A note on the stability indicator of the Atlantic meridional overturning circulation. J. Climate, 27, 969-975, https://doi.org/10.1175/JCLI-D-13-00181.1. 
,-- , and E. C. Brady, 2014: Why is the AMOC monostable in coupled general circulation models? J. Climate, 27, 2427 2443, https://doi.org/10.1175/JCLI-D-13-00264.1.

__- S.-P. Xie, Z. Liu, and J. Zhu, 2017: Overlooked possibility of a collapsed Atlantic meridional overturning circulation in warming climate. Sci. $A d v ., 3$, e1601666, https://doi.org/ 10.1126/sciadv.1601666.

Mahajan, S., R. Zhang, and T. L. Delworth, 2011: Impact of the Atlantic meridional overturning circulation (AMOC) on Arctic surface air temperature and sea ice variability. J. Climate, 24, 6573-6581, https://doi.org/10.1175/2011JCLI4002.1.

Marshall, J., J. R. Scott, K. C. Armour, J.-M. Campin, M. Kelley, and A. Romanou, 2015: The ocean's role in the transient response of climate to abrupt greenhouse gas forcing. Climate Dyn., 44, 22872299, https://doi.org/10.1007/s00382-014-2308-0.

McCusker, K. E., P. J. Kushner, J. C. Fyfe, M. Sigmond, V. V. Kharin, and C. M. Bitz, 2017: Remarkable separability of circulation response to Arctic sea ice loss and greenhouse gas forcing. Geophys. Res. Lett., 44, 7955-7964, https://doi.org/ 10.1002/2017GL074327.

Menary, M. B., and R. A. Wood, 2018: An anatomy of the projected North Atlantic warming hole in CMIP5 models. Climate Dyn., 50, 3063-3080, https://doi.org/10.1007/s00382017-3793-8.

Mikolajewicz, U., M. Vizcaíno, J. Jungclaus, and G. Schurgers, 2007: Effect of ice sheet interactions in anthropogenic climate change simulations. Geophys. Res. Lett., 34, L18706, https:// doi.org/10.1029/2007GL031173.

Muir, L. C., and A. V. Fedorov, 2017: Evidence of the AMOC interdecadal mode related to westward propagation of temperature anomalies in CMIP5 models. Climate Dyn., 48, 15171535, https://doi.org/10.1007/s00382-016-3157-9.

Neale, R. B., and Coauthors, 2010: Description of the NCAR Community Atmosphere Model (CAM 4.0). NCAR Tech. Note NCAR/TN-485, 212 pp.

Oudar, T., E. Sanchez-Gomez, F. Chauvin, J. Cattiaux, L. Terray, and C. Cassou, 2017: Respective roles of direct GHG radiative forcing and induced Arctic sea ice loss on the Northern Hemisphere atmospheric circulation. Climate Dyn., 49, 36933713, https://doi.org/10.1007/s00382-017-3541-0.

Overland, J. E., and M. Wang, 2010: Large-scale atmospheric circulation changes are associated with the recent loss of Arctic sea ice. Tellus, 62, 1-9, https://doi.org/10.1111/j.1600-0870.2009.00421.x.

Parkinson, C. L., and D. J. Cavalieri, 2008: Arctic sea ice variability and trends, 1979-2006. J. Geophys. Res., 113, C07003, https:// doi.org/10.1029/2007JC004558.

Polo, I., J. Robson, R. Sutton, and M. A. Balmaseda, 2014: The importance of wind and buoyancy forcing for the boundary density variations and the geostrophic component of the AMOC at $26^{\circ}$ N. J. Phys. Oceanogr., 44, 2387-2408, https:// doi.org/10.1175/JPO-D-13-0264.1.

Rahmstorf, S., 1996: On the freshwater forcing and transport of the Atlantic thermohaline circulation. Climate Dyn., 12, 799-811, https://doi.org/10.1007/s003820050144.

- J. E. Box, G. Feulner, M. E. Mann, A. Robinson, S. Rutherford, and E. J. Schaffernicht, 2015: Exceptional twentieth-century slowdown in Atlantic ocean overturning circulation. Nat. Climate Change, 5, 475-480, https://doi.org/ 10.1038/nclimate2554.

Roberts, C. D., L. Jackson, and D. McNeall, 2014: Is the 2004-2012 reduction of the Atlantic meridional overturning circulation significant? Geophys. Res. Lett., 41, 3204-3210, https://doi.org/ 10.1002/2014GL059473.
Schmidtko, S., G. C. Johnson, and J. M. Lyman, 2013: MIMOC: A global monthly isopycnal upper-ocean climatology with mixed layers. J. Geophys. Res., 118, 1658-1672, https://doi.org/ 10.1002/jgrc.20122.

Schmitt, R. W., P. S. Bogden, and C. E. Dorman, 1989: Evaporation minus precipitation and density fluxes for the North Atlantic. J. Phys. Oceanogr., 19, 1208-1221, https://doi.org/10.1175/ 1520-0485(1989)019<1208:EMPADF $>2.0 . C O ; 2$.

Scinocca, J. F., M. C. Reader, D. A. Plummer, M. Sigmond, P. J. Kushner, T. G. Shepherd, and A. R. Ravishankara, 2009: Impact of sudden Arctic sea-ice loss on stratospheric polar ozone recovery. Geophys. Res. Lett., 36, L24701, https://oi.org/ 10.1029/2009GL041239.

Screen, J. A., I. Simmonds, C. Deser, and R. Tomas, 2013: The atmospheric response to three decades of observed Arctic sea ice loss. J. Climate, 26, 1230-1248, https://doi.org/10.1175/ JCLI-D-12-00063.1.

Sévellec, F., and A. V. Fedorov, 2013: The leading, interdecadal eigenmode of the Atlantic meridional overturning circulation in a realistic ocean model. J. Climate, 26, 2160-2183, https:// doi.org/10.1175/JCLI-D-11-00023.1.

, and - 2015: Optimal excitation of AMOC decadal variability: Links to the subpolar ocean. Prog. Oceanogr., 132, 287-304, https://doi.org/10.1016/j.pocean.2014.02.006.

— T. Tuck, M. B. Jelloul, N. Grima, J. Vialard, and A. Weaver, 2008: Optimal surface salinity perturbations of the meridional overturning and heat transport in a global ocean general circulation model. J. Phys. Oceanogr., 38, 2739-2754, https:// doi.org/10.1175/2008JPO3875.1.

- A. V. Fedorov, and W. Liu, 2017: Arctic sea-ice decline weakens the Atlantic meridional overturning circulation. Nat. Climate Change, 7, 604-610, https://doi.org/10.1038/nclimate3353.

Shields, C. A., D. A. Bailey, G. Danabasoglu, M. Jochum, J. T. Kiehl, S. Levis, and S. Park, 2012: The low-resolution CCSM4. J. Climate, 25, 3993-4014, https://doi.org/10.1175/ JCLI-D-11-00260.1.

Smeed, D. A., and Coauthors, 2014: Observed decline of the Atlantic meridional overturning circulation 2004-2012. Ocean Sci., 10, 29-38, https://doi.org/10.5194/os-10-29-2014.

_ and Coauthors, 2018: The North Atlantic Ocean is in a state of reduced overturning. Geophys. Res. Lett., 45, 1527-1533, https://doi.org/10.1002/2017GL076350.

Smith, D. M., N. J. Dunstone, A. A. Scaife, E. K. Fiedler, D. Copsey, and S. C. Hardiman, 2017: Atmospheric response to Arctic and Antarctic sea ice: The importance of oceanatmosphere coupling and the background state. J. Climate, $\mathbf{3 0}$, 4547-4565, https://doi.org/10.1175/JCLI-D-16-0564.1.

Smith, R., and Coauthors, 2010: The Parallel Ocean Program (POP) reference manual. Los Alamos National Laboratory Tech. Rep. LAUR-10-01853, 140 pp.

Srokosz, M. A., and H. L. Bryden, 2015: Observing the Atlantic meridional overturning circulation yields a decade of inevitable surprises. Science, 348, 1255575, https://doi.org/10.1126/ science. 1255575 .

Stroeve, J., M. M. Holland, W. Meier, T. Scambos, and M. Serreze, 2007: Arctic sea ice decline: Faster than forecast. Geophys. Res. Lett., 34, L09501, https://doi.org/10.1029/2007GL029703.

Sun, L., M. Alexander, and C. Deser, 2018: Evolution of the global coupled climate response to Arctic sea ice loss during 19902090 and its contribution to climate change. J. Climate, 31, 7823-7843, https://doi.org/10.1175/JCLI-D-18-0134.1.

Suo, L., Y. Gao, D. Guo, and I. Bethke, 2017: Sea-ice free Arctic contributes to the projected warming minimum in the North 
Atlantic. Environ. Res. Lett., 12, 074004, https://doi.org/10.1088/ 1748-9326/aa6a5e.

Swart, N. C., J. C. Fyfe, E. Hawkins, J. E. Kay, and A. Jahn, 2015: Influence of internal variability on Arctic sea-ice trends. Nat. Climate Change, 5, 86-89, https://doi.org/10.1038/nclimate2483.

Timmermann, A., and H. Goosse, 2004: Is the wind stress forcing essential for the meridional overturning circulation? Geophys. Res. Lett., 31, L04303, https://doi.org/10.1029/2003GL018777.

Titchner, H. A., and N. A. Rayner, 2014: The Met Office Hadley Centre sea ice and sea surface temperature data set, version 2: 1. Sea ice concentrations. J. Geophys. Res. Atmos., 119, 2864 2889, https://doi.org/10.1002/2013JD020316.

Tomas, R. A., C. Deser, and L. Sun, 2016: The role of ocean heat transport in the global climate response to projected Arctic sea ice loss. J. Climate, 29, 6841-6859, https://doi.org/10.1175/ JCLI-D-15-0651.1.
Uttal, T., and Coauthors, 2002: Surface heat budget of the Arctic Ocean. Bull. Amer. Meteor. Soc., 83, 255-276, https://doi.org/ 10.1175/1520-0477(2002)083<0255:SHBOTA >2.3.CO;2

Wang, K., C. Deser, L. Sun, and R. A. Tomas, 2018: Fast response of the tropics to an abrupt loss of Arctic sea ice via ocean dynamics. Geophys. Res. Lett., 45, 4264-4272, https://doi.org/ 10.1029/2018GL077325.

Zhang, R., 2010: Latitudinal dependence of Atlantic meridional overturning circulation (AMOC) variations. Geophys. Res. Lett., 37, L16703, https://doi.org/10.1029/2010GL044474. 2015: Mechanisms for low-frequency variability of summer Arctic sea ice extent. Proc. Natl. Acad. Sci. USA, 112, 4570 4575, https://doi.org/10.1073/pnas.1422296112.

- and G. K. Vallis, 2006: Impact of great salinity anomalies on the low-frequency variability of the North Atlantic climate. J. Climate, 19, 470-482, https://doi.org/10.1175/JCLI3623.1. 